\title{
Chinese Provincial Difference in the Efficiency of Universities' Scientific and Technological Activities Based on DEA with Shared Input
}

\author{
Huan-huan Zhao $\mathbb{D}^{1},{ }^{1}$ Yong Liu, ${ }^{2}$ Jian Li, ${ }^{2}$ Xue-ge Guo, ${ }^{2}$ and Hai-jin Gui ${ }^{3}$ \\ ${ }^{1}$ School of Management, Wuxi Institute of Technology, Wuxi, Jiangsu 214122, China \\ ${ }^{2}$ School of Business Jiangnan University, Wuxi, Jiangsu 214122, China \\ ${ }^{3}$ Headmaster's Office, Wuxi Vocational College of Commerce, Wuxi, Jiangsu 214153, China \\ Correspondence should be addressed to Huan-huan Zhao; huan983405544@163.com
}

Received 15 September 2021; Revised 12 November 2021; Accepted 13 December 2021; Published 31 January 2022

Academic Editor: Goran D. Putnik

Copyright (c) 2022 Huan-huan Zhao et al. This is an open access article distributed under the Creative Commons Attribution License, which permits unrestricted use, distribution, and reproduction in any medium, provided the original work is properly cited.

\begin{abstract}
The universities' scientific and technological activities have become the key link of science and technology and economy, and the core of promoting the national innovation capability and competitiveness. To achieve high-quality development of China's science and technology, it is of great significance to measure the efficiency of universities' scientific and technological activities accurately and explore their regional differences. Based on the innovation value chain, we construct a two-stage efficiency measure index system of universities' scientific and technological activity, and then according to the universities' statistical data in China from 2010 to 2017, by taking provincial universities as the research object, we exploit a two-stage network DEA model with shared input to measure the provincial efficiency of universities' scientific and technological activities in China; what is more, we explore the provincial differences in efficiency of universities' scientific and technological activities. Finally, we extract the influencing factors on the efficiency of universities' scientific and technological activities using the dynamic panel data model. The results show that there are serious problems in the transformation between knowledge output and results in the universities' scientific and technological activities. The scientific and technological activities of regional universities in China are not balanced. For provincial universities' efficiency of scientific and technological activities, there exist great differences among different time and space, stages, and resource utilization modes. The endogenous factors such as policy system and technology service are much more important factors.
\end{abstract}

\section{Introduction}

With the introduction of the innovation-driven development strategy, technological innovation has become another important engine for country's economic development. As one of the most important nodes in the technological innovation system, universities play an irreplaceable role in basic knowledge research and technological innovation. However, for a long time, country's universities have always had problems such as imperfect scientific and technological innovation systems and mechanisms, low quality of innovation output, and low conversion rate of innovation achievements. In 2018, the Ministry of Education, the Ministry of Finance, and the National Development and Reform Commission jointly issued the "Guiding Opinions on Accelerating the Construction of 'Double First-Class' in Higher Education Institutions," which clearly requires that the construction of "Double First-Class" be included in the major regional development strategy and guide the "Double First-Class." The construction of universities and universities in the region coordinated to promote and develop together, improve the innovation output of universities, and give full play to the role of universities in the transfer and transformation of collaborative innovation results.

Universities' scientific and technological activities are vital contents for university construction. They are of great 
significance to promote regional scientific and technological innovation and the development of regional economy and society $[1,2]$. However, there exists a serious "two skin" problem between science and technology and economic development, and there is a huge waste of scientific and technological innovation and achievements [3]. According to the statistical data of Chinese universities, the Chinese universities' technology transformation is still in the primary stage of development, and there are still some problems such as the lower transformation rate of scientific and technological achievements. According to the 2009-2019 University Science and Technology Statistics, the annual number of scientific and technologic achievements (the number of patents granted) in Chinese universities has increased from less than 20,000 in 2008 to 184,934 in 2018, which takes on a relatively rapid growth rate. However, there is only less than $1 / 10$ to be really transformed and industrialized. Compared with the commercialization and industrialization rate of $60 \%-80 \%$ in developed countries, the impetus of economic development has not yet been shown by the scientific and technological progress of universities in China, and there is a huge waste of the elements of scientific and technological development; the separation of knowledge output and achievement transformation is serious, which directly affects the utilization efficiency of scientific and technological resources in universities, as well as the transformation of economic development mode and the strategic deployment of building an innovative country [4]. Therefore, accurately grasping the efficiency of scientific and technological activities in China's universities, identifying the regional differences and important key factors, which affect the efficiency of universities' scientific and technological activities, and generating "deep knowledge" to guide or assist decision-making have become a great theoretical and practical significance to promote the transformation of scientific and technological achievements into real productive forces and accelerate their commercialization and industrialization.

\section{Literature Review}

Universities' scientific and technological activities are an important part of the activities and construction content [5]. The effective development and improvement of universities' scientific and technological activities depend on the support and input of $\mathrm{R} \& \mathrm{D}$ resources. The rational allocation of scientific and technological resources is an important prerequisite and guarantee for the development of universities' science and technology [6]. To promote the rational allocation of scientific and technological resources and improve the efficiency of universities' scientific and technological activities, many scholars both home and abroad discuss the related problems and give solutions.

They mainly focus on the four aspects of the relationship between scientific and technological activities and economic development, measuring and evaluating methods, the construction of efficiency measure index system, and the identification of the influencing factors for the efficiency of scientific and technological activities. (1) In terms of the relationship between scientific and technological activities and economic development, the main research contents include $\mathrm{R} \& \mathrm{D}$ and corporate value [7], R\&D and management work [8], scientific and technological activities and technological innovation $[9,10]$, and scientific and technological activities and productivity [11]. The positive or negative relationship between input-output activities of scientific and technological activities and economic development is discussed through data analysis and other empirical studies. (2) In the efficiency evaluation and measurement of universities' scientific and technological activities, the main methods and models are constructed, including stochastic frontier model [12-14], DEA model [15-19], evidence reasoning rule [20], and multiattribute decision evaluation method [21], fuzzy inputoutput analysis method [22], and best and worst method (BWM) [23]. Although these measures and evaluation methods to some extent solve the problem of efficiency evaluation and measurement, they cannot reflect the lag relationship between influencing factors and efficiency. At the same time, these methods have specific requirements for the evaluation objects and data. To solve the problem of lag in analyzing the efficiency evaluation of universities' scientific and technological activities, Liu et al. constructed a correlation analysis model with hysteresis effect, measured the lag period of the efficiency input indexes of universities' scientific and technological activities, and discussed its influencing factors [24], but this method cannot well analyze the stage difference and the efficiency level. (3) In the construction of the efficiency measure index system of scientific and technological activities, the factors on the efficiency of scientific and technological activities are extracted mainly from the perspective of input and output. These factors mainly include the investment of science and technology, the input of scientific research personnel $[8,25-31]$, the equipment investment $[26,27]$, policies, laws, and regulations [28], patents [27], and treatise [28], and then, some efficiency measure index systems are established. The constructed measure index systems mostly start from either R\&D efficiency or the efficiency of scientific and technological achievement transformation, but they are not discussed as a whole. The measure index systems are mostly aimed at the scientific and technological activities of research institutions or enterprises, it is difficult to meet the requirements of dealing with the efficiency problems of scientific and technological activities in universities, and some data are difficult to obtain. (4) In the research about the influencing factors on the efficiency of scientific and technological activities, they mainly focus on the political system [14, 30], laws and regulations [32], policies [33], scientific researchers, funds, patents, and technical service staff [25-29], scientific and technological intermediary organizations [34], and other factors. In general, it is mainly manifested in government support, intellectual property protection, $R \& D$ investment ( $\&$ \& personnel and $\mathrm{R} \& \mathrm{D}$ expenditure), technology transformation investment (achievement application and transformation personnel and funds), industry-universityresearch cooperation, and so on. 
According to the above discussion and analysis, the existing research mainly takes universities' scientific and technological activities as a single stage or process to analyze and measure efficiency and its influencing factors, and it does not consider different stages. To overcome the shortcomings, from the perspective of innovation value chain, according to the universities' statistical data in China from 2010 to 2017, we exploit a DEA model with shared input to measure the efficiency of R\&D and achievement transformation of universities' scientific and technological activities to analyze the regional difference and then identify the influencing factors using GMM.

\section{Theoretical Model}

3.1. Analysis of the Efficiency of Universities' Scientific and Technological Activities Based on the Innovation Value Chain. Based on the theory of innovation value chain [35], universities' scientific and technological activities can be regarded as an innovation chain composed of innovative knowledge flow path. In the innovation value chain, there exist six organization nodes of knowledge source, design concept, technical refinement, experimental prototype, technology incubation, and commercialization of scientific and technological achievements [36, 37]. In the chain, universities, enterprises, governments, and intermediaries are responsible for different transformation functions [38]. The knowledge source, design concept, and technical refinement belong to the R\&D investment of universities. The experimental prototype belongs to the output of the results, and technology incubation and commercialization of scientific and technological achievements belong to the transformation of achievements. Therefore, the innovation value chain passes three key points of $R \& D$ investment, scientific research output, and scientific research profits. According to the law of universities' scientific and technological activities, it can be divided into two stages of $R \& D$ and achievement transformation [16].

At the R\&D stage, universities invest scientific research staff, funds, and equipment. Then, it will produce scientific and technological achievements and achieve the intermediate output of scientific and technological activities (patents, papers, books, etc.). The achievement transformation stage is the process that universities transform their scientific and technological achievements into economic benefits through the application of scientific and technological achievements, service funds, and personal efforts. According to the above analysis, the first stage realizes the output of R\&D achievements (patents, papers, books, etc.) through four links of "knowledge source," "design concept," "technical refinement," and "experimental prototype." Also, the first stage can promote the achievements of scientific and technological transformation and increase its value; the second stage realizes the commercialization and industrialization of scientific and technological achievements through three links of "experimental prototype," "technology incubation," and "commercialization of scientific and technological achievements." At this stage, the experimental prototypes are constantly improving and becoming mature, and technology promotion and application are realized through technology incubation. Ultimately, the commercial value of the achievements will be enhanced in the process of commercialization. The benefits will be increased by providing technology services, selling results, and transferring technology. According to the above analysis, we can obtain the two-stage universities' scientific and technological activities based on the innovation value chain shown in Figure 1.

According to Figure 1, the R\&D efficiency is the ratio of intermediate output such as patents, papers, and monographs to innovation investment in scientific and technological activities. The R\&D efficiency can measure the ability of transforming scientific and technological innovation investment into scientific and technological output. The transformation efficiency of university's technological achievements is the ratio of the scientific and technological economic output (such as the number of signed contracts and the amount of the patent sale contract) to the sum investment of intermediate output patent, the application of $\mathrm{R} \& \mathrm{D}$ achievements, and the scientific and technological services (mainly refers to the investment of personnel and funding). The efficiency of the transformation of university's technological achievements reflects the standard of transforming the investment in scientific and technological services and intermediate output into economic value.

3.2. A Two-Stage Efficiency Measure Index System for Universities'Scientific and Technological Activities. According to the above analysis from the perspective of innovation value chain, we take 30 provinces in China as the research objects (Tibet, Hong Kong, Macao, and Taiwan are not included in this study due to insufficient data). For R\&D investment indexes, $\mathrm{R} \& \mathrm{D}$ full-time personnel, $\mathrm{R} \& \mathrm{D}$ expenditure stocks, number of $R \& D$ institutions in higher education institutions, application of R\&D achievements, and the number of technology service projects are chosen. For the indexes of intermediate products, we select the amount of published scientific works, the number of academic papers published, and the number of patents granted. For the final output variable, we determine the number of patent sale contracts and patent sale income (contract amount). Then, a two-stage efficiency measure index system for universities' scientific and technological activities can be established.

(1) $R \& D$ investment indexes. The input factors at the R\&D stage mainly include personnel investment and funding input $[34,37]$. In this study, we select $\mathrm{R} \& \mathrm{D}$ full-time personnel and R\&D expenditure as a measure index [35]. Because $R \& D$ expenditures often have a cumulative effect on time, that is, the current $\mathrm{R} \& \mathrm{D}$ expenditure will not only affect the output of the university's R\&D and transformation now, but also affect the R\&D and transformation in future years. Therefore, we exploit the stock index of $R \& D$ capital investment to measure R\&D expenditures and use the perpetual inventory method to calculate. Before measuring the stock of R\&D funds, 


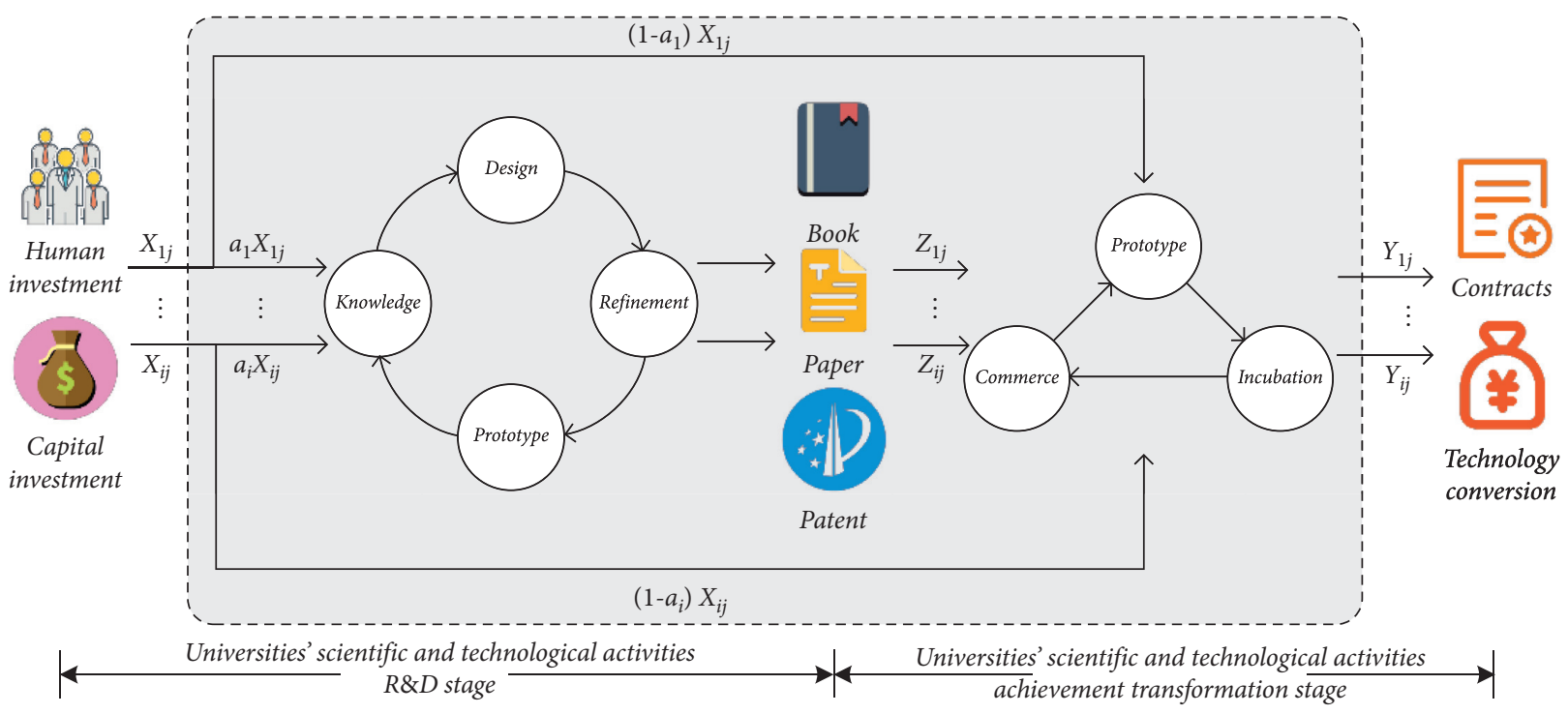

FIgURE 1: Two-stage universities' scientific and technological activities based on innovation value chain.

it is necessary to use the deflator of $\mathrm{R} \& \mathrm{D}$ price. The base period stock is equal to the ratio of the $R \& D$ expenditure internal expenditure through the deflator to the sum of the $R \& D$ expenditure growth rate and the depreciation rate. Under the assumption that the average lag period is one year, the calculation formula of the perpetual inventory method is $K_{t}=E_{t-1}+(1-\delta) K_{t-1} . K_{t}$ and $K_{t-1}$ stand for the current and present R\&D capital stock with lagged phase, respectively. $\delta$ is the depreciation rate for the R\&D capital stock. The current R\&D capital stock is the sum of the R\&D capital stock of the lag phase and the R\&D present value of the lag phase.

(2) Intermediate indexes. The output of the R\&D stage refers to the scientific knowledge created and summarized through R\&D activities. During this stage, researchers can form outputs such as scientific papers and works through basic research activities. The technology and invention output represented by patents, software, etc., can be obtained through application research activities such as applied research and experiments. The research achievements will become public goods of human knowledge by means of public publication, research reports, etc. Also, the transformation of their achievements can be accomplished by means of business consultation. This study selects the number of publishing technology monographs and the number of academic papers published as measure indexes [39]. Considering that the output of applied and experimental research can be presented by patents, and patents are further subdivided into three categories: inventions, utility models, and designs, in terms of technical content, we take the patent authorization amount as a measure index.
(3) Final output index. At the transformation stage, the scientific and technological achievements are mainly patents, and most of them are converted by selling and transferring. According to the existing researches, the number of contracts signed in the process of transformation, the contract amount, and final technology transfer income constitute the index system for measuring the transformation value of scientific and technological achievements. We choose the number of sale contracts and technology transfer income as the final output indexes.

3.3. Analysis of the Influencing Factors on Efficiency of Scientific and Technological Activities. Universities' scientific and technological activities are an important way to improve regional innovation capability and competitiveness, but its development is affected and restricted by many factors. To identify these important factors and bottleneck factors on the efficiency, by combining relevant literature information, we give the influencing factors shown as in Table 1.

According to Table 1 and related theory, some explanations and illustrations are as follows:

(1) The quality of R\&D personnel. As a knowledge-intensive activity, scientific and technological activities require lots of high-quality talents. The higher the $R \& D$ human resource quality is, the better it will be for the development of scientific and technological activities, the creation of new knowledge, and the development of new technologies. Furthermore, the higher R\&D human resource quality can promote scientific and technological activities [40]. This study selects the proportion of R\&D personnel from scientists and engineers to represent the quality of R\&D personnel.

(2) The communication of scientific and technological activities. The communication of universities' 
TABLE 1: Evaluation index system of technological innovation ability in the high-tech industry.

\begin{tabular}{|c|c|c|c|}
\hline \multicolumn{2}{|r|}{ R\&D stage } & \multicolumn{2}{|c|}{ Technical transformation stage } \\
\hline First-level index & Second-level index & First-level index & Second-level index \\
\hline \multirow{5}{*}{$\begin{array}{l}\text { Technological } \\
\text { innovation input }\end{array}$} & The average number of employees $x_{1}^{0}$ & \multirow{5}{*}{$\begin{array}{l}\text { Innovative achievement } \\
\text { input }\end{array}$} & $\begin{array}{l}\text { Number of invention patent } \\
\text { applications } x_{1}^{2}\end{array}$ \\
\hline & The number of firms with R\&D activities $x_{2}^{1}$ & & Number of enterprises $x_{2}^{2}$ \\
\hline & $\mathrm{R} \& \mathrm{D}$ personnel equivalent to full time $x_{3}^{1}$ & & $\begin{array}{l}\text { Number of new product } \\
\text { development projects } x_{3}^{2}\end{array}$ \\
\hline & Internal R\&D expenditure $x_{4}^{1}$ & & Investment in fixed asset $x_{4}^{2}$ \\
\hline & New product development expenditures $x_{5}^{1}$ & & $\begin{array}{c}\text { Number of valid invention } \\
\text { patents } x_{5}^{2}\end{array}$ \\
\hline \multirow{4}{*}{$\begin{array}{l}\text { Technological } \\
\text { innovation output }\end{array}$} & $\begin{array}{l}\text { Number of patent applications } x_{6}^{1} \\
\text { Number of invention patent applications } x_{7}^{1}\end{array}$ & \multirow{4}{*}{$\begin{array}{l}\text { Intermediate } \\
\text { technological input }\end{array}$} & $\begin{array}{l}\text { Technology introduction funds } x_{6}^{2} \\
\text { Digest and absorb funds } x_{7}^{2}\end{array}$ \\
\hline & $\begin{array}{l}\text { Number of valid invention patents } x_{8}^{1} \\
\text { Number of new product development }\end{array}$ & & Buy domestic technical funds $x_{8}^{2}$ \\
\hline & projects $x_{9}^{1} a$ & & Technical renovation funds $x_{9}^{2}$ \\
\hline & $\begin{array}{l}\text { New fixed assets } x_{10}^{1} \\
\text { The number of enterprises with R\&D }\end{array}$ & & New product sale revenue $x_{10}^{2}$ \\
\hline \multirow{3}{*}{$\begin{array}{l}\text { Innovative environment } \\
\text { support }\end{array}$} & institutions $x_{11}^{1}$ & \multirow{3}{*}{ Industrialization benefits } & Export delivery value $x_{11}^{2}$ \\
\hline & R\&D institutions $x_{12}^{1}$ & & \\
\hline & $\begin{array}{c}\mathrm{R} \& \mathrm{D} \text { institution expenditure } x_{13}^{1} \\
\mathrm{R} \& \mathrm{D} \text { institution equipment value } x_{14}^{1}\end{array}$ & & Profit $x_{12}^{2}$ \\
\hline
\end{tabular}

scientific and technological activities helps researchers to acquire new ideas, new knowledge, and new skills, and they will learn together and promote each other. Besides, communication may generate new theoretical assumptions and new method paths [41]. The communication of scientific and technological activities is mainly reflected in the number of meetings and cooperation. Therefore, this study selects the number of scientific and technological cooperation researchers as an index to measure the communication of scientific and technological activities in university and studies its impact on the universities' scientific and technological activities.

(3) The government's support for university scientific and technological activities. The government's supports such as policy support, institutional support, and financial support guide and coordinate universities' scientific and technological activities [42]. Among them, the effect of funds is more direct to the universities' scientific and technological activities, and they can better reflect the government's support for universities. Therefore, this study selects the proportion of government funds in all funds for scientific and technological activities in universities to measure the government's support for university scientific and technological activities.

(4) The connection between universities and enterprises. Universities and enterprises establish cooperative relations through cooperative development and technology transfer. On the one hand, the connection will achieve complementary resources and share risks and form technological synergies. On the other hand, the connection will promote the dissemination, absorption, and utilization of knowledge within the innovation system. Also, the connection can improve overall innovation efficiency [43]. To explore the influence of the connection between universities and enterprises on the scientific and technological activities, this study selects the proportion of funds entrusted by enterprises in the whole funds of universities' scientific and technological activities as a measure index.

(5) The number of $R \& D$ topics. The R\&D topic of universities is a carrier, which exists in the whole process of the investment and final achievement transformation $[27,28]$. This study selects the total number of R\&D topics such as basic research, applied research, and experimental research as the measurement indexes.

(6) Regional economic development. Regional economic development will affect the innovation and development level of innovation entities. The more intense the market competition is, the stronger the innovation drive of universities will be, and the demand for universities to seek innovative cooperation will be more urgent. Also, the intense competition of market can promote the scientific research and innovation and accelerate the transformation of scientific and technological achievements. This study selects the regional GDP per capita as an analysis index.

\section{Research Method}

4.1. A Two-Stage Network DEA Model with Shared Input. Universities' scientific and technological activities are a multistage, complex system with intermediate input-output factors and subsystems coupled with each other, and the traditional DEA model measures the efficiency of the university's scientific and technological activity system as a 
"black box." It does not consider the reinvestment of intermediate products, so that it cannot understand the impact of the efficiency substages of the internal operation process on the overall system efficiency, and it cannot determine the source of efficiency loss [44]. The network DEA model is based on the traditional data envelopment analysis model to decompose the whole process including the decision-making unit into several subprocesses or stages. Each stage is distinguished by its own input and output process, and all stages are related by intermediate elements $[16,45,46]$. Due to the superiority of the twostage network DEA model, we will use this model to open the "black box" of R\&D activity efficiency to open up the application field of the model, which has certain theoretical significance.

Assume there are $n$ decision-making units (DMU, which refer to 30 provinces in mainland China (excluding Tibet) in 2009-2016). Each decision-making unit $\mathrm{DMU}_{r}(r=1,2,3, \ldots, n)$ has $I$ type of innovation investment $x_{i r}(i=1,2,3, \ldots, I), J$ type of intermediate output $z_{j r}(j=1,2,3, \ldots, J)$, and $K$ type of innovation output $y_{k r}(k=1,2,3, \ldots, K)$. The innovation investment of $\mathrm{DMU}_{r}(r=1,2,3, \ldots, n)$ is not fully utilized in the innovation $\mathrm{R} \& \mathrm{D}$ stage, but in a certain proportion in the two stages of innovation $\mathrm{R} \& \mathrm{D}$ and innovation transformation. The two parts $\alpha_{i} X_{i r}$ and $\left(1-\alpha_{i}\right) X_{i r}$ of innovation investment are the discretionary inputs of $\mathrm{R} \& \mathrm{D}$ and transformation stages. $\tau_{i}^{1}$ and $\tau_{i}^{2}(i=1,2,3, \ldots, I)$ represent the weight of the two-part innovation investment in their stages. $v_{k}(k=1,2,3, \ldots, K)$ represents the weight of output $y_{k r}$ in the final innovation transformation stage. $\omega_{j}^{1}$ and $\omega_{j}^{2} \quad(j=1,2,3, \ldots, J)$ indicate the weight of the intermediate product in the $\mathrm{R} \& \mathrm{D}$ and transformation stages, respectively.

Then, $\mathrm{DMU}_{r}(r=1,2,3, \ldots, n)$ inputs and outputs in the innovation and development phase are $\sum_{i=1}^{I} \tau_{i}^{1} \alpha_{i} X_{i r}$ and $\sum_{j=1}^{J} \omega_{j}^{1} z_{j r}$. The inputs and outputs in the transformation phase of the results are $\sum_{i=1}^{I} \tau_{i}^{2}\left(1-\alpha_{i}\right) X_{i r}+\sum_{j=1}^{J} \omega_{j}^{2} z_{j r}$ and $\sum_{k=1}^{K} v_{k} y_{k r}$, respectively.

According to the linear programming theory, it can be concluded that the R\&D efficiency $E_{s}^{1}$ of the $s$ th decisionmaking unit $\mathrm{DMU}_{s}$ is variable when the scale returns are variable:

$$
E_{s}^{1}=\frac{\left(\max \sum_{j=1}^{J} \omega_{j}^{1} z_{j s}-\mu_{1}\right)}{\sum_{i=1}^{I} \tau_{i}^{1} \alpha_{i} X_{i s}} .
$$

Let $t=1 / \sum_{i=1}^{I} \tau_{i}^{1} \alpha_{i} X_{i s}$, and then, let $T_{i}^{1} \alpha_{i}=\mu_{i}^{1}$ and $T_{i}^{2} \alpha_{i}=\mu_{i}^{2}$; the fraction is converted to a linear form by $C^{2}$ transformation. In the case of variable scale returns, innovative $R \& D$ efficiency of $\mathrm{DMU}_{s}$ is the optimal value for the following linear programming problem:

$$
\begin{aligned}
& E_{s}^{1}= \max \sum_{j=1} \omega_{j}^{1} z_{j s}-\mu_{A}, \\
& \text { s.t. }\left\{\begin{array}{l}
\sum_{i=1}^{l} \mu_{i}^{1} X_{i s}=1, \\
\sum_{i=1}^{l} \mu_{i}^{1} X_{i p}-\left(\sum_{j=1}^{J} W_{j}^{1} z_{j p}-\mu_{A}\right) \geq 0, \quad p=1,2,3, \ldots, n, \\
\sum_{i=1}^{I} T_{i}^{2} X_{i p}-\sum_{i=1}^{l} \mu_{i}^{2} X_{i p}+\sum_{j=1}^{J} W_{j}^{2} z_{j p}-\left(\sum_{k=1}^{K} V_{k} y_{k p}-\mu_{B}\right) \geq 0, \quad p=1,2,3, \ldots, n, \\
\mu_{i}^{1}, T_{i}^{2}, \mu_{i}^{2}, W_{j}^{1}, W_{j}^{2}, \quad V_{k} \geq \varepsilon>0,
\end{array}\right.
\end{aligned}
$$

where $T_{i}^{1}=t \tau_{i}^{1}, T_{i}^{2}=t \tau_{i}^{2}, W_{j}^{1}=t \omega_{j}^{1}, W_{j}^{2}=t \omega_{j}^{2}, V_{k}=t \nu_{k}$, $\mu_{A}=t \mu_{1}$, and $\mu_{B}=t \mu_{2}$. According to the above formula (2), we can calculate the R\&D efficiency of the decision-oriented evaluation unit based on the input orientation. Similarly, the transformation efficiency of the $\mathrm{DMU}_{s}$ is the optimal value of the following linear programming problem: 


$$
\begin{aligned}
& E_{s}^{2}=\max \sum_{k=1}^{K} v_{k} y_{k s}-\mu_{B}, \\
& \text { s.t. }\left\{\begin{array}{l}
\sum_{i=1}^{I} T_{i}^{2} X_{i s}-\sum_{i=1}^{I} \mu_{i}^{2} X_{i s}+\sum_{j=1}^{J} W_{j}^{2} z_{j s}=1, \\
\sum_{i=1}^{l} \mu_{i}^{1} X_{i p}-\left(\sum_{j=1}^{J} W_{j}^{1} z_{j p}-\mu_{A}\right) \geq 0, \quad p=1,2,3 \ldots n, \\
\sum_{i=1}^{l} T_{i}^{2} X_{i p}-\sum_{i=1}^{l} \mu_{i}^{2} X_{i p}+\sum_{j=1}^{J} W_{j}^{2} z_{j p}-\left(\sum_{k=1}^{K} V_{k} y_{k p}-\mu_{B}\right) \geq 0, \quad p=1,2,3, \ldots n, \\
\mu_{i}^{1}, T_{i}^{2}, \mu_{i}^{2}, W_{j}^{1}, W_{j}^{2}, \quad V_{k} \geq \varepsilon>0,
\end{array}\right.
\end{aligned}
$$

where $T_{i}^{1}=t^{\prime} \tau_{i}^{1}, T_{i}^{2}=t^{\prime} \tau_{i}^{2}, W_{j}^{1}=t^{\prime} \omega_{j}^{1}, W_{j}^{2}=t^{\prime} \omega_{j}^{2}, V_{k}=t^{\prime} v_{k}$, and $t V_{k}=t^{\prime} v_{k}=1 / \sum_{i=1}^{I} \tau_{i}^{2} X_{i s}-\sum_{=1}^{I} \mu_{i}^{2} X_{i s}+\sum_{j=1}^{J} \omega_{j}^{2} z_{j s}=1$.

4.2. GMM. According to the above analysis of the influencing factors, the R\&D human quality (HQ), the university's scientific and technological activity exchange (COM), the government's support for university innovation activities (GOV), universities and the linkage relationship between enterprises (ENT), R\&D topics (PRO), regional economic development (ECO), and other indexes are explanatory variables. The dynamic panel regression model of the system GMM is constructed as follows:

$$
\begin{aligned}
E_{i t}^{1}\left(\text { or }_{i t}^{2}\right)= & \beta_{0}+\beta_{1} E_{i t-1}^{1}\left(\text { or } E_{i t-1}^{2}\right)+\beta_{2} \mathrm{HQ}_{i t} \\
& +\beta_{3} \mathrm{COM}_{i t}+\beta_{4} \mathrm{GOV}_{i t}+\beta_{5} \mathrm{ENT}_{i t}+\beta_{6} \mathrm{PRO}_{i t} \\
& +\beta_{7} \mathrm{ECO}_{i t}+\varepsilon_{i t},
\end{aligned}
$$

where $E_{i t}^{1}$ and $E_{i t}^{2}$ are the efficiency values of R\&D and achievement transformation of universities' scientific and technological activities in each province, $\beta_{0}$ is a constant term, $\beta_{1} \sim \beta_{7}$ is the coefficient to be evaluated, and $\varepsilon_{i t}$ is the disturbance term. Since the model is missing or difficult to measure some important explanatory variables (such as government policies and systems), it is easy to cause endogenous problems. We compensate for the problems by adding lags. So, this study constructs a firstorder auto-regression model with lag first-order variables as explanatory variables. In addition, there may be endogenous problems between expenditure and economic development, government support, enterprise support, and efficiency value. To obtain a stable fitting result, we take the economic development intensity, government support, and enterprise support as the instrumental variables.

\section{Empirical Analysis}

In this study, we take universities in 30 provinces (Tibet, Hong Kong, Macao, and Taiwan are not included in the scope of this study due to lack of data) as the research objects. According to "Science and Technology Statistical
Yearbook of Universities" and "China Education Statistical Yearbook" and other statistical data from 2010 to 2017, we use the two-stage efficiency measure index system and DEA model to measure the efficiency and, respectively, analyze the efficiency difference in universities' scientific and technological activities from the aspects of national, eastern, central, western, northeastern, and provincial areas, and then, we use the panel data model to extract the important factors.

\subsection{Measurement of the Efficiency of Universities' Scientific and Technological Activities}

5.1.1. Correlation Test. To measure the efficiency by DEA, we should test the selected sample data to see whether the output increases along with the increase in the input. Based on the data, we can calculate the Pearson correlation coefficient and the Spearman correlation coefficient for each input-output variable shown in Table 2. According to Table 2, the results show that input variable index and output variable index are positively correlated at the significance level of $1 \%$, which meets the isotonic requirements of the DEA model. Taking the Pearson correlation coefficient as an example, in the R\&D stage of scientific and technological activities in universities, input index research, full-time personnel $(H)$, and $\mathrm{R} \& \mathrm{D}$ expenditure capital stock (EXP) have a significant positive correlation with output indexes such as monograph $(B)$, thesis (PAP), and patent (PAT), respectively, and the correlation coefficients are $0.764,0.712,0.904,0.868,0.678$, and 0.710 . In the transformation stage of universities' scientific and technological activities, input indexes such as monograph (B), thesis (PAP), and patent (PAT) are significantly positively correlated with output indexes such as contract $(\mathrm{CON})$ and technology transfer $(\mathrm{P})$. The correlation coefficients are, respectively, 0.594, 0.707, 0.786, 0.622, 0.760, and 0.563 . This shows that the DEA efficiency measurement model constructed by the sample data in this study is effective.

The Pearson correlation coefficient is on the lower left, and the Spearman correlation coefficient is on the upper right. The correlation between the input and output indexes is shown in Table 2. 
TABLE 2: Correlation between the input and output indexes.

\begin{tabular}{|c|c|c|c|c|c|c|c|}
\hline Variable & $\mathrm{H}$ & EXP & B & PAP & PAT & $\mathrm{CON}$ & $\mathrm{P}$ \\
\hline $\mathrm{H}$ & 1 & $0.906^{* *}$ & $0.779^{* *}$ & $0.910^{* *}$ & $0.816^{* *}$ & $0.818^{* *}$ & $0.757^{* *}$ \\
\hline EXP & $0.862^{* *}$ & 1 & $0.815^{* *}$ & $0.933^{* *}$ & $0.896^{* *}$ & $0.861^{* *}$ & $0.799^{* *}$ \\
\hline B & $0.764^{* *}$ & $0.712^{* *}$ & 1 & $0.878^{* *}$ & $0.742^{* *}$ & $0.732^{* *}$ & $0.705^{* *}$ \\
\hline PAP & $0.904^{* *}$ & $0.868^{* *}$ & $0.866^{* *}$ & 1 & $0.853^{* *}$ & $0.862^{* *}$ & $0.808^{* *}$ \\
\hline PAT & $0.678^{* *}$ & $0.710^{* *}$ & $0.660^{* *}$ & $0.759^{* *}$ & 1 & $0.832^{* *}$ & $0.765^{* *}$ \\
\hline $\mathrm{CON}$ & $0.584^{* *}$ & $0.638^{* *}$ & $0.594^{* *}$ & $0.707^{* *}$ & $0.786^{* *}$ & 1 & $0.820^{* * *}$ \\
\hline $\mathrm{P}$ & $0.734^{* *}$ & $0.850^{* *}$ & $0.622^{* *}$ & $0.760^{* *}$ & $0.563^{* *}$ & $0.555^{* *}$ & 1 \\
\hline
\end{tabular}

${ }^{* *}$ indicates a significant correlation at the 0.01 level (two-tailed).

5.1.2. Measurement of the Efficiency of Universities' Scientific and Technological Activities. Based on the constructed model, the comprehensive efficiency, R\&D efficiency, transformation efficiency, and other values of scientific and technical activities can be calculated in Python, and these values are shown in Tables 3-5.

As can be seen from Table 3, the comprehensive efficiency value is 0.556 , which illustrates there is still a lot of room to optimize the efficiency of the universities' scientific and technological activities all over the country; from Tables 4 and 5, R\&D efficiency value and transformation efficiency value of universities all over the country are 0.748 and 0.747 , respectively, indicating that there is a small gap in the efficiency value between the $R \& D$ stage and the achievement transformation stage in the national universities.

In terms of comprehensive efficiency, at the regional level, the comprehensive efficiency values of universities' scientific and technological activities in the eastern area (its efficiency value is 0.669 ) and the western area (its efficiency value is 0.557 ) are relatively higher, ranking above the national average. In contrast, the central area (its efficiency value is 0.490) and the northeast area (its efficiency value is 0.311 ) are significantly lower; in the aspect of the efficiency value of $R \& D$, the western area (its efficiency value is 0.814 ) and the central area (its efficiency value is 0.753 ) are relatively higher, which shows that the R\&D level of universities in the western and central areas are relatively strong. The eastern area (its efficiency value is 0.747 ) is already below the national average, while the northeast area (its efficiency value is 0.496 ) is significantly lower, indicating that the utilization rate of resources in the R\&D stage of universities' scientific and technological activities in the northeast area is weak in the whole country, and the calculation results are also different from the traditional impression of "East Middle West" decreasing.

In terms of comprehensive efficiency, at the provincial level, the efficiency values of universities' scientific and technological activities in Jiangsu, Qinghai, Ningxia, Hainan, and Beijing are all above 0.9 , which are relatively higher, and these provinces are mainly distributed in the eastern and western areas. While the efficiency values of Gansu, Yunnan, Heilongiiang, Hunan, Liaoning, and Guizhou provinces are all less than 0.4, these provinces are mainly distributed in the western and northeast areas. The comprehensive level of universities' scientific and technological activities in the western and central regions is relatively dispersed, and the comprehensive efficiency of most provinces in the eastern region is relatively higher, while that in the northeast area is generally low; on the aspect of efficiency value of R\&D, Jiangsu, Henan, Hainan, Qinghai, Xinjiang, and other provinces have maintained the most efficient decision-making units of the year for many years, and these provinces are mainly distributed in the eastern and western areas. In particular, there is no efficiency value of $R \& D$ under 0.6 in the western area, while the efficiency values of the eastern provinces such as Shanghai, Zhejiang, and Tianjin are concentrated on 0.6 or less.

\subsection{The Analysis of Efficiency Difference in Universities' Scientific and Technological Activities}

5.2.1. The Efficiency Difference in Regional Universities. According to the efficiency from 2010 to 2016, the comprehensive efficiency values of universities' scientific and technological activities can be calculated. As shown in Figure 2, there is no obvious fluctuation in comprehensive efficiency, which always fluctuates around 0.6. The average efficiency value remains at 0.556 , and there is still a long way to go from the optimal production efficiency of fully efficient use of resources. From the efficiency of scientific and technological activities in various regions of the country over the years, the comprehensive efficiency and stage efficiency of the national and four regional universities' scientific and technological activities can be calculated, and they are shown in Figure 3.

According to Figure 3, the transformation efficiency in the eastern region is superior to that of $\mathrm{R} \& \mathrm{D}$, which indicates that the R\&D efficiency of the eastern area still has the room to improve, and it restricts the efficiency growth of the eastern area. The efficiency of the achievement transformation in the central area is low, while the efficiency of the achievement transformation in the western area is relatively low, indicating that the western area should make more improvements at the stage of achievement transformation, which mainly focus on the technology commercialization and the technology implementation stage. In the northeast area, the $\mathrm{R} \& \mathrm{D}$ efficiency restrains the improvement of comprehensive efficiency, so more improvements should be made at the R\&D stage.

According to the above analysis, the eastern area is ranked relatively top at both the R\&D and transformation stages, which is entirely consistent with what was previously thought. This is because that the eastern area has more national key 
TABle 3: Provincial universities' comprehensive efficiency (2010 2016).

\begin{tabular}{|c|c|c|c|c|c|c|c|c|c|}
\hline \multirow{2}{*}{ Area } & \multicolumn{9}{|c|}{ Comprehensive efficiency } \\
\hline & 2010 & 2011 & 2012 & 2013 & 2014 & 2015 & 2016 & Means & Rank \\
\hline Entire country & 0.572 & 0.529 & 0.533 & 0.553 & 0.624 & 0.551 & 0.534 & 0.556 & \\
\hline East area & 0.697 & 0.647 & 0.620 & 0.657 & 0.713 & 0.650 & 0.698 & 0.669 & \\
\hline Central area & 0.657 & 0.529 & 0.509 & 0.463 & 0.487 & 0.441 & 0.342 & 0.490 & \\
\hline West area & 0.497 & 0.492 & 0.516 & 0.570 & 0.701 & 0.594 & 0.530 & 0.557 & \\
\hline Northeast area & 0.257 & 0.269 & 0.349 & 0.319 & 0.319 & 0.283 & 0.379 & 0.311 & \\
\hline Beijing (BJ) & 1.000 & 1.000 & 1.000 & 1.000 & 0.655 & 0.642 & 1.000 & 0.900 & 5 \\
\hline Tianjin (TJ) & 0.317 & 0.338 & 0.339 & 0.362 & 0.360 & 0.454 & 0.490 & 0.380 & 21 \\
\hline Hebei (HE) & 0.450 & 0.731 & 0.829 & 0.970 & 0.944 & 0.723 & 0.581 & 0.747 & 8 \\
\hline Shanxi (SX) & 0.472 & 0.510 & 0.587 & 0.572 & 0.453 & 0.536 & 0.577 & 0.530 & 16 \\
\hline Inner Mongolia (IM) & 0.423 & 0.271 & 0.302 & 0.363 & 1.000 & 0.458 & 0.223 & 0.434 & 18 \\
\hline Liaoning (LN) & 0.334 & 0.279 & 0.633 & 0.303 & 0.283 & 0.139 & 0.169 & 0.306 & 26 \\
\hline Jilin (JL) & 0.330 & 0.307 & 0.260 & 0.342 & 0.317 & 0.512 & 0.580 & 0.378 & 22 \\
\hline Heilongjiang (HL) & 0.108 & 0.221 & 0.155 & 0.312 & 0.358 & 0.197 & 0.388 & 0.248 & 28 \\
\hline Shanghai (SH) & 0.555 & 0.550 & 0.568 & 0.632 & 0.657 & 0.677 & 0.687 & 0.618 & 10 \\
\hline Jiangsu (JS) & 1.000 & 1.000 & 1.000 & 1.000 & 1.000 & 1.000 & 1.000 & 1.000 & 1 \\
\hline Zhejiang (ZJ) & 0.530 & 0.500 & 0.290 & 0.345 & 0.430 & 0.430 & 0.509 & 0.433 & 19 \\
\hline Anhui (AH) & 1.000 & 0.511 & 0.554 & 0.677 & 0.691 & 0.700 & 0.272 & 0.629 & 9 \\
\hline Fujian $(\mathrm{FJ})$ & 0.317 & 0.353 & 0.417 & 0.432 & 0.431 & 0.475 & 0.506 & 0.419 & 20 \\
\hline Jiangxi (JX) & 0.320 & 0.595 & 0.271 & 0.298 & 0.428 & 0.297 & 0.230 & 0.348 & 23 \\
\hline Shandong (SD) & 0.802 & 0.366 & 0.386 & 0.456 & 1.000 & 0.267 & 0.208 & 0.498 & 17 \\
\hline Henan (HA) & 0.791 & 0.464 & 0.578 & 0.624 & 0.708 & 0.548 & 0.525 & 0.605 & 12 \\
\hline Hubei (HB) & 1.000 & 0.964 & 0.721 & 0.298 & 0.382 & 0.370 & 0.279 & 0.574 & 14 \\
\hline Hunan $(\mathrm{HN})$ & 0.359 & 0.132 & 0.341 & 0.310 & 0.260 & 0.196 & 0.170 & 0.253 & 27 \\
\hline Guangdong (GD) & 1.000 & 0.634 & 0.442 & 0.507 & 0.822 & 1.000 & 1.000 & 0.772 & 7 \\
\hline Guangxi (GX) & 0.737 & 0.759 & 0.844 & 1.000 & 1.000 & 0.985 & 0.925 & 0.893 & 6 \\
\hline Hainan (HI) & 1.000 & 1.000 & 0.929 & 0.867 & 0.829 & 0.834 & 1.000 & 0.923 & 4 \\
\hline Chongqing (CQ) & 0.487 & 0.655 & 0.720 & 0.453 & 0.467 & 0.607 & 0.656 & 0.578 & 13 \\
\hline Sichuan (SC) & 0.158 & 0.219 & 0.288 & 0.484 & 0.537 & 0.269 & 0.459 & 0.345 & 24 \\
\hline Guizhou (GZ) & 0.275 & 0.220 & 0.227 & 0.334 & 0.656 & 0.275 & 0.272 & 0.323 & 25 \\
\hline Yunnan (YN) & 0.173 & 0.217 & 0.248 & 0.381 & 0.223 & 0.133 & 0.229 & 0.229 & 29 \\
\hline Shaanxi (SN) & 0.466 & 0.541 & 0.417 & 0.438 & 0.614 & 0.776 & 0.588 & 0.549 & 15 \\
\hline Gansu (GS) & 0.249 & 0.224 & 0.241 & 0.165 & 0.210 & 0.197 & 0.196 & 0.212 & 30 \\
\hline Qinghai (QH) & 1.000 & 1.000 & 1.000 & 1.000 & 1.000 & 1.000 & 1.000 & 1.000 & 2 \\
\hline Ningxia (NX) & 1.000 & 1.000 & 1.000 & 1.000 & 1.000 & 0.838 & 0.825 & 0.952 & 3 \\
\hline Xinjiang (XJ) & 0.498 & 0.310 & 0.392 & 0.656 & 1.000 & 1.000 & 0.464 & 0.617 & 11 \\
\hline
\end{tabular}

laboratories, scientific research institutions, and national key support policies and funds, and the eastern area takes advantage of its convenient transportation advantages, open markets, and the talent reserve and other advantages to make the cooperation among enterprises, universities, and scientific research institutes closer and more efficient, so that the industry-university-research collaborative innovation is at a better level in the regions. Although the western area is more efficient at the R\&D stage, the volume of input and output is relatively small and involves a relatively centralized and single category. The central area are relatively lack of government support, development opportunities, and the innovation environment, technology management. In addition, the central area's intellectual property protection is not as good as that of the eastern and western regions. There is still more room for improvement in terms of patent output and so on. The problems in the northeast area are more serious, and most of them focus on the serious shortage of patent output.

To clearly analyze the changes in the two stages over time, based on the efficiency values of each stage in the past years, the change trend charts of the efficiency at R\&D and transformation stages are obtained, which are shown in Figure 4 and 5, respectively.

According to Figure 4, the R\&D efficiency of regional universities' scientific and technological activities shows an overall upward trend as time goes on, and some areas approach 1 as a whole tend, but the ways of the rise are not the same. The eastern area shows a wave-like rise, while the central area shows a zigzag rise in the adjustment. Across the country, the overall level fluctuates between 0.706 and 0.791 , and the average level is 0.748 . It can be seen that the western area as a whole has already been higher than the national level, while the northeast area as a whole is lower than the national level and the eastern and western areas are around the national level.

As can be seen from Figure 5, the transformation efficiency of Chinese universities' scientific and technological achievements varies from each other, showing a great instability. Generally speaking, the national transformation efficiency hovers between 0.686 and 0.822 , which is less than that at the R\&D stage, which also indicates that there is a problem of separation between the knowledge output and 
Table 4: Provincial Universities’ R\&D efficiency (2010 2016).

\begin{tabular}{|c|c|c|c|c|c|c|c|c|c|}
\hline \multirow{2}{*}{ Area } & \multicolumn{9}{|c|}{ R\&D efficiency } \\
\hline & 2010 & 2011 & 2012 & 2013 & 2014 & 2015 & 2016 & Means & Rank \\
\hline Entire country & 0.721 & 0.706 & 0.739 & 0.759 & 0.758 & 0.760 & 0.791 & 0.748 & \\
\hline East area & 0.724 & 0.712 & 0.732 & 0.782 & 0.730 & 0.755 & 0.795 & 0.747 & \\
\hline Central area & 0.779 & 0.687 & 0.750 & 0.752 & 0.787 & 0.739 & 0.779 & 0.753 & \\
\hline West area & 0.734 & 0.754 & 0.798 & 0.826 & 0.855 & 0.863 & 0.871 & 0.814 & \\
\hline Northeast area & 0.554 & 0.550 & 0.524 & 0.448 & 0.440 & 0.446 & 0.510 & 0.496 & \\
\hline Beijing (BJ) & 1.000 & 1.000 & 1.000 & 1.000 & 0.655 & 0.642 & 1.000 & 0.900 & 9 \\
\hline Tianjin (TJ) & 0.317 & 0.338 & 0.339 & 0.362 & 0.360 & 0.454 & 0.490 & 0.380 & 28 \\
\hline Hebei (HE) & 0.677 & 0.731 & 0.829 & 0.970 & 0.944 & 1.000 & 1.000 & 0.879 & 11 \\
\hline Shanxi (SX) & 0.553 & 0.520 & 0.604 & 0.572 & 0.663 & 0.540 & 0.671 & 0.589 & 25 \\
\hline Inner Mongolia (IM) & 0.523 & 0.703 & 0.793 & 0.868 & 1.000 & 1.000 & 1.000 & 0.841 & 12 \\
\hline Liaoning (LN) & 1.000 & 1.000 & 1.000 & 0.691 & 0.645 & 0.459 & 0.563 & 0.765 & 15 \\
\hline Jilin (JL) & 0.330 & 0.307 & 0.260 & 0.342 & 0.317 & 0.512 & 0.580 & 0.378 & 29 \\
\hline Heilongjiang (HL) & 0.331 & 0.344 & 0.313 & 0.312 & 0.359 & 0.366 & 0.388 & 0.345 & 30 \\
\hline Shanghai (SH) & 0.555 & 0.550 & 0.568 & 0.632 & 0.657 & 0.677 & 0.687 & 0.618 & 24 \\
\hline Jiangsu (JS) & 1.000 & 1.000 & 1.000 & 1.000 & 1.000 & 1.000 & 1.000 & 1.000 & 1 \\
\hline Zhejiang (ZJ) & 0.530 & 0.500 & 0.511 & 0.526 & 0.430 & 0.430 & 0.513 & 0.491 & 26 \\
\hline Anhui (AH) & 1.000 & 0.511 & 0.554 & 0.677 & 0.691 & 0.700 & 0.616 & 0.678 & 20 \\
\hline Fujian (FJ) & 0.354 & 0.381 & 0.429 & 0.432 & 0.431 & 0.475 & 0.506 & 0.430 & 27 \\
\hline Jiangxi (JX) & 0.552 & 0.595 & 0.614 & 0.754 & 0.790 & 0.599 & 0.656 & 0.651 & 21 \\
\hline Shandong (SD) & 0.802 & 0.631 & 0.647 & 0.902 & 1.000 & 0.870 & 0.750 & 0.800 & 14 \\
\hline Henan (HA) & 1.000 & 1.000 & 1.000 & 1.000 & 1.000 & 1.000 & 1.000 & 1.000 & 1 \\
\hline Hubei (HB) & 1.000 & 0.964 & 0.848 & 0.838 & 0.879 & 0.869 & 1.000 & 0.914 & 8 \\
\hline Hunan $(\mathrm{HN})$ & 0.567 & 0.532 & 0.880 & 0.669 & 0.696 & 0.727 & 0.731 & 0.686 & 18 \\
\hline Guangdong (GD) & 1.000 & 0.991 & 1.000 & 1.000 & 0.822 & 1.000 & 1.000 & 0.973 & 6 \\
\hline Guangxi (GX) & 0.737 & 0.759 & 0.844 & 1.000 & 1.000 & 0.985 & 0.925 & 0.893 & 10 \\
\hline Hainan (HI) & 1.000 & 1.000 & 1.000 & 1.000 & 1.000 & 1.000 & 1.000 & 1.000 & 1 \\
\hline Chongqing (CQ) & 0.487 & 0.655 & 0.720 & 0.687 & 0.683 & 0.607 & 0.656 & 0.642 & 23 \\
\hline Sichuan (SC) & 0.584 & 0.649 & 0.635 & 0.670 & 0.676 & 0.756 & 0.819 & 0.684 & 19 \\
\hline Guizhou (GZ) & 0.759 & 0.564 & 0.693 & 0.726 & 0.861 & 0.808 & 0.795 & 0.744 & 16 \\
\hline Yunnan (YN) & 0.491 & 0.483 & 0.501 & 0.701 & 0.719 & 0.827 & 0.788 & 0.644 & 22 \\
\hline Shaanxi (SN) & 0.719 & 0.851 & 0.880 & 0.748 & 0.760 & 0.889 & 0.951 & 0.828 & 13 \\
\hline Gansu (GS) & 0.770 & 0.634 & 0.710 & 0.689 & 0.707 & 0.780 & 0.822 & 0.730 & 17 \\
\hline Qinghai (QH) & 1.000 & 1.000 & 1.000 & 1.000 & 1.000 & 1.000 & 1.000 & 1.000 & 1 \\
\hline Ningxia (NX) & 1.000 & 1.000 & 1.000 & 1.000 & 1.000 & 0.838 & 0.825 & 0.952 & 7 \\
\hline Xinjiang (XJ) & 1.000 & 1.000 & 1.000 & 1.000 & 1.000 & 1.000 & 1.000 & 1.000 & 1 \\
\hline
\end{tabular}

the achievement transformation; the transformation efficiency of the scientific and technological achievements in the four major regions shows great differences, and the northeast and central areas have the largest range of change, while the western area is relatively stable and its transformation efficiency is relatively higher than that in other areas, and it also shows that the western area has a better efficiency at the stage of achievement transformation.

5.2.2. The Analysis of the Provincial Difference in the Efficiency of Universities' Scientific and Technological Activities

(1) The Analysis of the Provincial Difference in the Comprehensive Efficiency. To analyze the efficiency of scientific and technological activities in provincial universities of China more clearly and measure the spatial and temporal differences in provincial efficiency, this study uses the $K$-means clustering algorithm. It selects the comprehensive efficiency values of 30 provincial and municipal universities as the index variable. The closer their settlement results are, the more similar they are. The clustering results are shown in Figure 6.

From Figure 6, according to the comprehensive efficiency of universities' scientific and technological activities in various provinces of China, the efficiency can be divided into three categories of good, middle, and poor. The provinces and cities of good category include Beijing, Jiangsu, Guangxi, Hainan, Qinghai, and Ningxia, while the provinces and cities of the middle category are Hebei, Shanxi, Shanghai, Anhui, Shandong, Henan, Hubei, Guangdong, Chongqing, Shaanxi, and Xinjiang; and the provinces and cities of the poor category cover Tianjin, Inner Mongolia, Liaoning, Jilin, Heilongjiang, Zhejiang, Fujian, Jiangxi, Hunan, Sichuan, Guizhou, Yunnan, and Gansu. According to the classification results, the overall efficiency level of some western areas is better than that of some cities in the central and eastern areas, which is consistent with the regional analysis above and also indicates that it is different from the previous view that "east is strong and west is weak," such as Qinghai, Ningxia, and Guangxi. The northeast and parts of the west have the 
TABle 5: Provincial Universities' transformation efficiency (2010 2016).

\begin{tabular}{|c|c|c|c|c|c|c|c|c|c|}
\hline \multirow{2}{*}{ Area } & \multicolumn{9}{|c|}{ Transformation efficiency } \\
\hline & 2010 & 2011 & 2012 & 2013 & 2014 & 2015 & 2016 & Means & Rank \\
\hline Entire country & 0.778 & 0.754 & 0.724 & 0.736 & 0.822 & 0.729 & 0.686 & 0.747 & \\
\hline East area & 0.956 & 0.915 & 0.851 & 0.853 & 0.983 & 0.886 & 0.885 & 0.904 & \\
\hline Central area & 0.809 & 0.782 & 0.705 & 0.640 & 0.624 & 0.622 & 0.448 & 0.661 & \\
\hline West area & 0.660 & 0.624 & 0.624 & 0.662 & 0.787 & 0.676 & 0.612 & 0.664 & \\
\hline Northeast area & 0.553 & 0.640 & 0.710 & 0.813 & 0.812 & 0.613 & 0.767 & 0.701 & \\
\hline Beijing (BJ) & 1.000 & 1.000 & 1.000 & 1.000 & 1.000 & 1.000 & 1.000 & 1.000 & 1 \\
\hline Tianjin (TJ) & 1.000 & 1.000 & 1.000 & 1.000 & 1.000 & 1.000 & 1.000 & 1.000 & 1 \\
\hline Hebei (HE) & 0.664 & 1.000 & 1.000 & 1.000 & 1.000 & 0.723 & 0.581 & 0.853 & 15 \\
\hline Shanxi (SX) & 0.853 & 0.981 & 0.972 & 1.000 & 0.684 & 0.992 & 0.860 & 0.906 & 12 \\
\hline Inner Mongolia (IM) & 0.809 & 0.385 & 0.381 & 0.418 & 1.000 & 0.458 & 0.223 & 0.525 & 24 \\
\hline Liaoning (LN) & 0.334 & 0.279 & 0.633 & 0.438 & 0.439 & 0.302 & 0.301 & 0.389 & 27 \\
\hline Jilin (JL) & 1.000 & 1.000 & 1.000 & 1.000 & 1.000 & 1.000 & 1.000 & 1.000 & 1 \\
\hline Heilongjiang (HL) & 0.325 & 0.642 & 0.496 & 1.000 & 0.996 & 0.538 & 1.000 & 0.714 & 17 \\
\hline Shanghai $(\mathrm{SH})$ & 1.000 & 1.000 & 1.000 & 1.000 & 1.000 & 1.000 & 1.000 & 1.000 & 1 \\
\hline Jiangsu (JS) & 1.000 & 1.000 & 1.000 & 1.000 & 1.000 & 1.000 & 1.000 & 1.000 & 1 \\
\hline Zhejiang (ZJ) & 1.000 & 1.000 & 0.567 & 0.655 & 1.000 & 1.000 & 0.993 & 0.888 & 14 \\
\hline Anhui (AH) & 1.000 & 1.000 & 1.000 & 1.000 & 1.000 & 1.000 & 0.441 & 0.920 & 11 \\
\hline Fujian (FJ) & 0.896 & 0.926 & 0.973 & 1.000 & 1.000 & 1.000 & 1.000 & 0.971 & 9 \\
\hline Jiangxi (JX) & 0.579 & 1.000 & 0.442 & 0.395 & 0.542 & 0.495 & 0.351 & 0.543 & 23 \\
\hline Shandong (SD) & 1.000 & 0.580 & 0.597 & 0.505 & 1.000 & 0.307 & 0.277 & 0.609 & 21 \\
\hline Henan (HA) & 0.791 & 0.464 & 0.578 & 0.624 & 0.708 & 0.548 & 0.525 & 0.605 & 22 \\
\hline Hubei (HB) & 1.000 & 1.000 & 0.850 & 0.356 & 0.435 & 0.426 & 0.279 & 0.621 & 19 \\
\hline Hunan $(\mathrm{HN})$ & 0.633 & 0.249 & 0.388 & 0.463 & 0.374 & 0.269 & 0.232 & 0.373 & 28 \\
\hline Guangdong (GD) & 1.000 & 0.640 & 0.442 & 0.507 & 1.000 & 1.000 & 1.000 & 0.798 & 16 \\
\hline Guangxi (GX) & 1.000 & 1.000 & 1.000 & 1.000 & 1.000 & 1.000 & 1.000 & 1.000 & 1 \\
\hline Hainan (HI) & 1.000 & 1.000 & 0.929 & 0.867 & 0.829 & 0.834 & 1.000 & 0.923 & 10 \\
\hline Chongqing (CQ) & 1.000 & 1.000 & 1.000 & 0.659 & 0.684 & 1.000 & 1.000 & 0.906 & 12 \\
\hline Sichuan (SC) & 0.270 & 0.337 & 0.454 & 0.722 & 0.795 & 0.356 & 0.560 & 0.499 & 25 \\
\hline Guizhou (GZ) & 0.362 & 0.390 & 0.327 & 0.460 & 0.762 & 0.340 & 0.342 & 0.426 & 26 \\
\hline Yunnan (YN) & 0.352 & 0.450 & 0.495 & 0.543 & 0.310 & 0.161 & 0.290 & 0.372 & 29 \\
\hline Shaanxi (SN) & 0.648 & 0.636 & 0.474 & 0.586 & 0.808 & 0.873 & 0.618 & 0.663 & 18 \\
\hline Gansu (GS) & 0.324 & 0.354 & 0.339 & 0.240 & 0.297 & 0.253 & 0.238 & 0.292 & 30 \\
\hline Qinghai (QH) & 1.000 & 1.000 & 1.000 & 1.000 & 1.000 & 1.000 & 1.000 & 1.000 & 1 \\
\hline Ningxia (NX) & 1.000 & 1.000 & 1.000 & 1.000 & 1.000 & 1.000 & 1.000 & 1.000 & 1 \\
\hline Xinjiang (XJ) & 0.498 & 0.310 & 0.392 & 0.656 & 1.000 & 1.000 & 0.464 & 0.617 & 20 \\
\hline
\end{tabular}

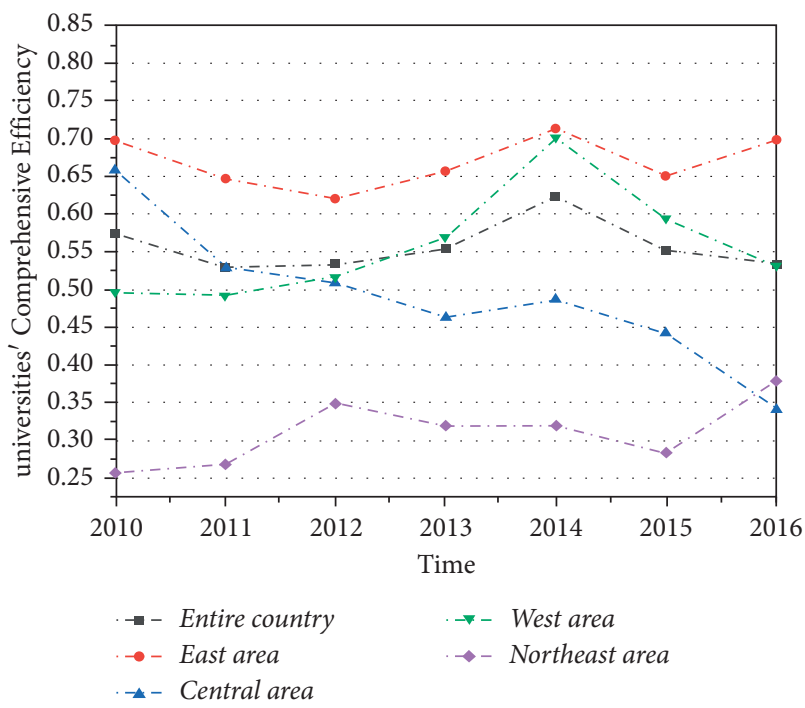

Figure 2: Universities' scientific and technological activity comprehensive efficiency of the country and the four major regions (2010-2016).

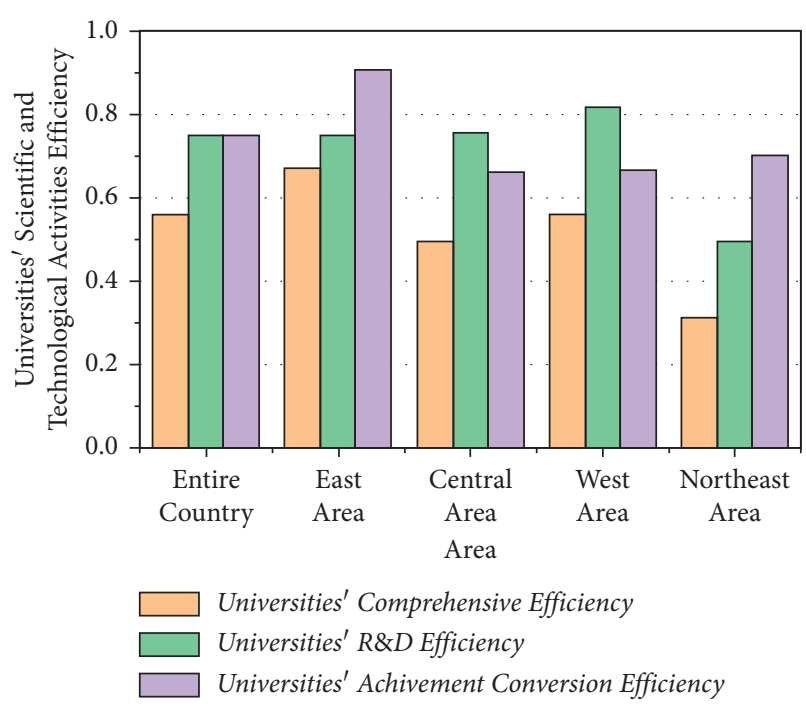

FIGURE 3: Universities' scientific and technological activity efficiency of the country and subregion. 


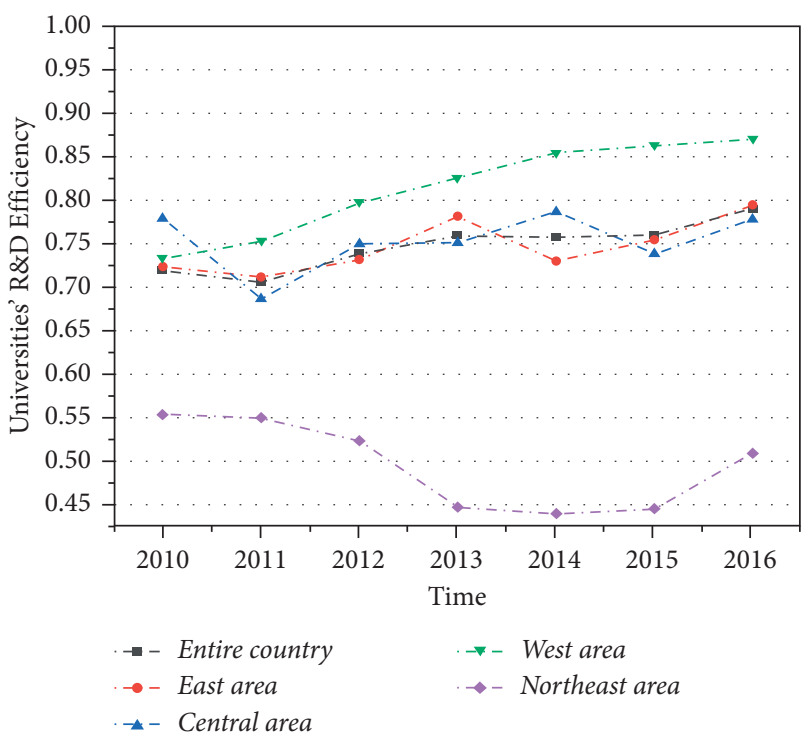

FIGURE 4: Universities' scientific and technological activity R\&D efficiency of the country and the four major regions (2010-2016).

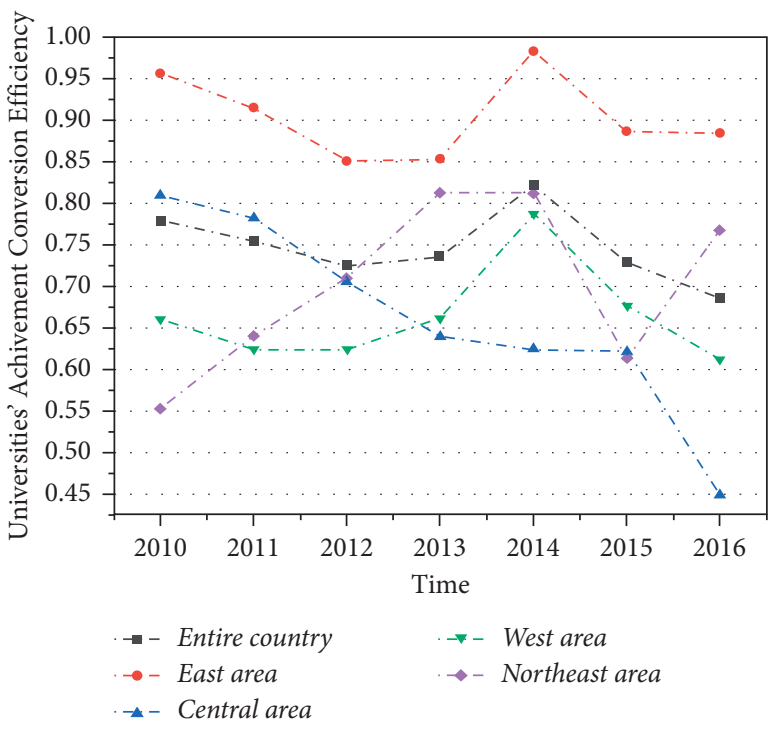

FIgURE 5: Universities' scientific and technological activity achievement transformation efficiency of the country and the four major regions (2010-2016).

lowest efficiency, such as Liaoning, Jilin, and Sichuan. The reason for this result may lay in more traditional efficiency analysis models. Starting from two stages, this study considers the input-output influence at the R\&D stage and the input-output impact at the transformation stage and adopts the two-stage input-sharing relevance. On the whole, the efficiency of the best areas is mainly distributed in the eastern coastal area and the Midwest, and the regions with good efficiency are mainly distributed in the southeast, and its efficiency level gap is not big compared with the areas with better efficiency. We need to do a good job at the stage of achievement transformation in these areas with good efficiency. There are 13 areas with poorer efficiency, and all of which have room for further improvement.
(2) The Analysis of the Provincial Differences at Different Time and Space of the Comprehensive Efficiency. To analyze the development trend of the overall efficiency of provincial universities' scientific and technological activities, we depicted the evolution of comprehensive efficiency of universities' scientific and technological activities with the change in color intensity according to the overall efficiency values of 30 provinces and cities in the past years, and the trend map can be obtained and shown in Figure 7. According to Figure 7, the efficiency of provincial universities' scientific and technological activities is not stable and the differences are great, but on the whole, the parts of the blue are gradually increasing and the color of most areas is gradually deepening, indicating that the efficiency values are increasing. Efficiency is getting higher and higher because of paying more and more attention to innovation input and transformation into intermediate output, experience accumulation, and improvement of methods. At the same time, we can also see that efficiency values in some places have not changed much, the level of efficiency values is low, and there are no obvious signs of improvement, so it is necessary to further increase investment in innovation, promote the construction of high-level talents and innovative teams, introduce high-level talents, and innovate team building and management mechanisms. In terms of distribution, most of the dark blue and dark areas are concentrated in the east-central and some western areas, which have good infrastructure, talent reserves, and markets. Therefore, for these areas, on the one hand, they should continue to maintain their current advantages; on the other hand, they should be aggressive and improve the quality of the transformation efficiency of universities' scientific and technological activities to better serve the universities and society. While light colors and light blues are mainly distributed in the northeast and some central regions, for these areas, on the one hand, they should start from their own situation to improve the intensity of investment in R\&D and implement measures with precision. On the other hand, they could learn from the experience of the universities with good performance in surrounding provinces and cities.

(3) The Analysis of the Provincial and Spatial Differences in the R\&D Efficiency. At the R\&D stage, from the perspective of economic and social development theory, the R\&D efficiency in various provincial regions has an overall upward trend with the passage of time, and some provinces and cities tend to be closer to 1, such as Jiangsu, Henan, Hainan, Qinghai, Xinjiang, and other provinces and cities. In terms of average value, the average efficiency in 30 provinces at the first stage during 2010-2016 is 0.748 , indicating that the overall level of R\&D efficiency in the whole country is relatively high at the first stage.

To clearly show the current situation and structure and relation of the efficiency of universities' scientific and technological activities, it is necessary to make cluster analysis on the average values of comprehensive efficiency in every province of China. It also adopts a clustering algorithm based on $K$-means. The clustering results are shown in Figure 8.

According to the efficiency of R\&D in various provincial universities and Figure 8, 30 provinces in China are divided 


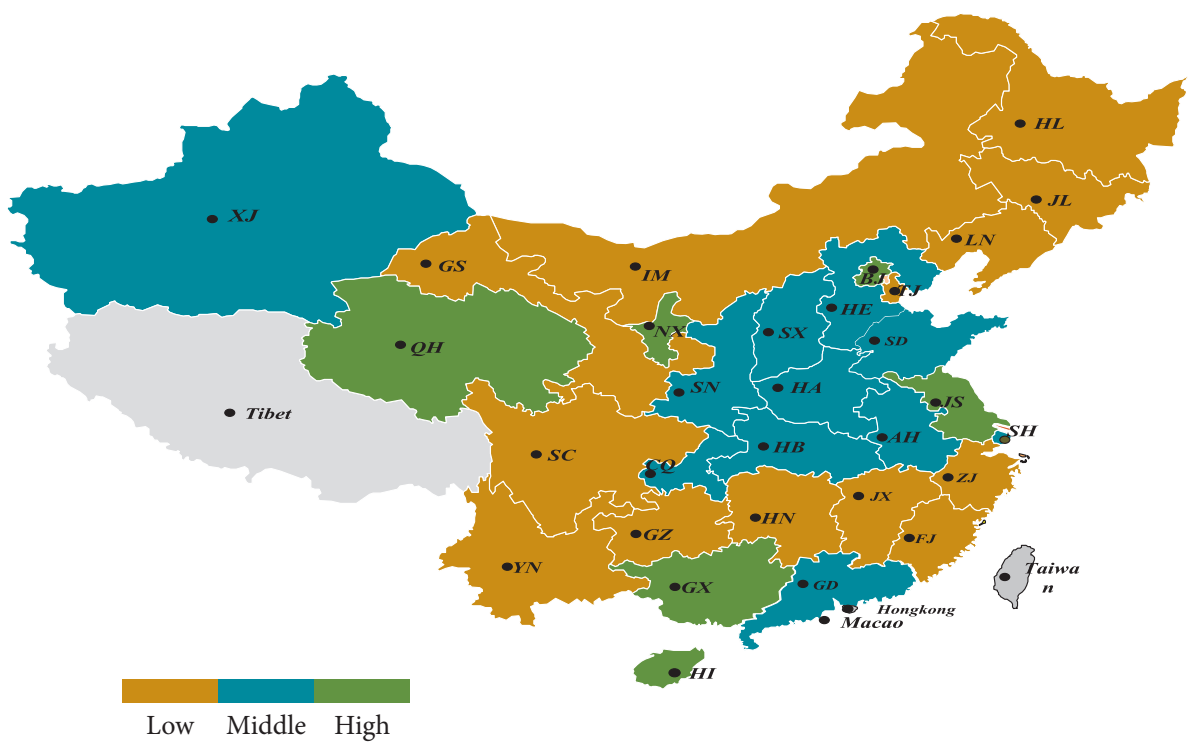

FIGURE 6: Clustering results of comprehensive efficiency.

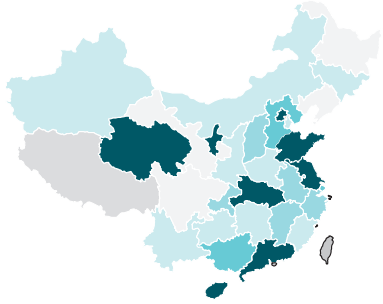

2009

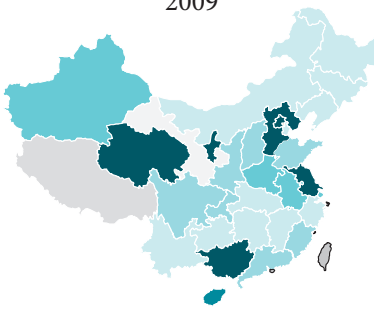

2013

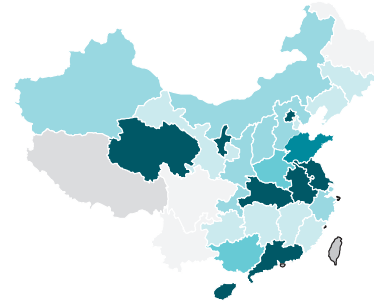

2010

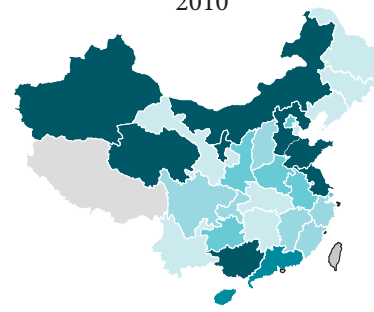

2014

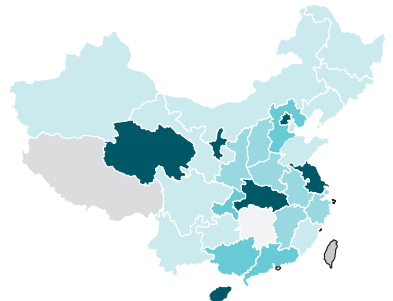

2011

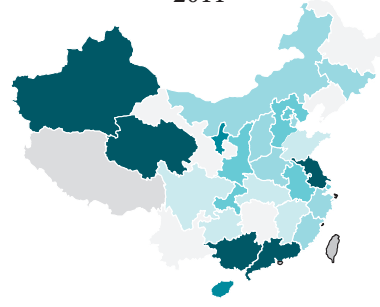

2015

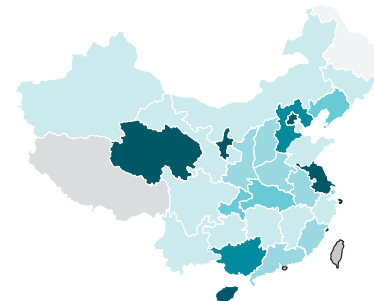

2012

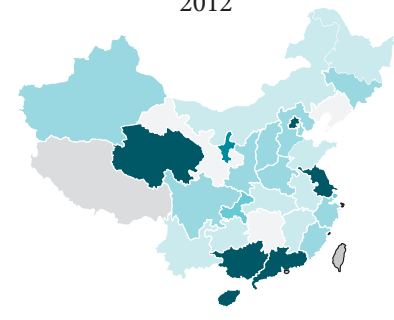

2016

Efficience of province

FIgURE 7: Spatial and temporal evolution trend of universities' comprehensive efficiency.

into three categories: good, medium, and poor. Among them, the good category mainly includes Beijing, Jiangsu, Guangxi, Hainan, Qinghai, Ningxia, Hebei, Henan, Hubei, Guangdong, Shaanxi, Xinjiang, and Inner Mongolia; the provinces in the middle category are Shanxi, Shanghai, Anhui, Shandong, Chongqing, Liaoning, Jiangxi, Hunan, Sichuan, Guizhou, Yunnan, and Gansu; and the poor category covers Tianjin, Jilin, Heilongjiang, Zhejiang, and Fujian. According to the clustering results, the first category accounts for $43.3 \%$ of the total, indicating that the R\&D efficiency of universities in these provinces and cities is relatively good. These regions include Beijing, Jiangsu, and other areas where universities gather together. They are the places where high-tech intellectual property rights are concentrated, which enhances the scientific R\&D of these places. From the perspective of the middle category, this category mainly includes some central cities and a large number of western cities, accounting for $40 \%$ of the country's provinces and cities. In terms of distribution, the first and second categories account for $83.3 \%$, indicating that the development of universities' scientific and technological activities in most provinces and cities is well carried out at the first stage, which is also in line with the strategy of vigorously developing science and technology advocated by the state. The poor category mainly includes the northeast provinces. This situation may be related to the backward 


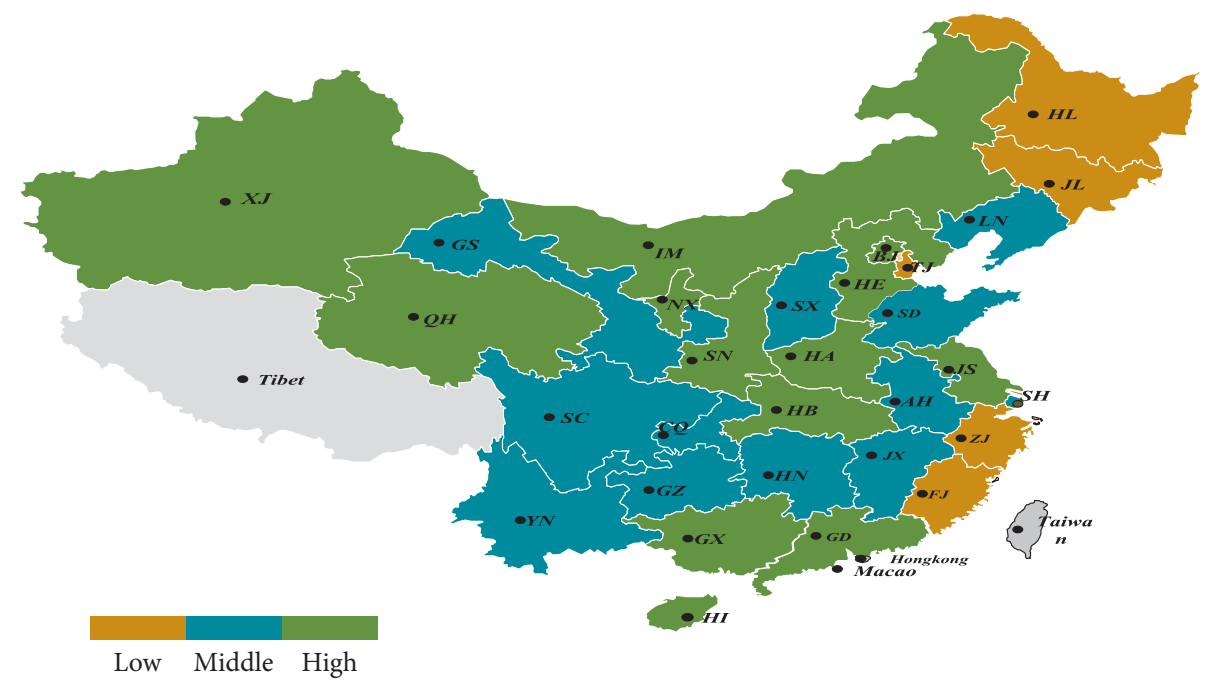

FIGURE 8: Provincial clustering results of R\&D efficiency.

economic development and the outdated creating efficiency of intellectual property achievements caused by the limited scientific research force.

In terms of distribution, the first and second categories from east to west are mainly distributed in the east, central, and western areas, while the lightest colors are mainly distributed in the western area. From the north to the south, the distribution of the second category is mostly in the south, and the first and third categories are mostly in the north. Therefore, from the division of the east, the west, the north, and the south, the efficiency level of universities' scientific and technological activities is related to the development of local economy and science and technology. This occurs because of the objective conditions. The geography, economy, culture, information, and other advantages in the eastern regions are superior to those in the central and western cities, and under the guidance of policies, the investment in scientific research and education is the largest in the eastern region. In fact, the efficiency of the three categories is getting closer and closer as time goes on, which means that the differences between regions are getting smaller and smaller.

(4) The Analysis of the Provincial and Spatial Differences in the Transformation Efficiency. Compared with the R\&D efficiency, the transformation efficiency has a great change. The average transformation efficiency of 30 provinces and cities is 0.747 , of which 14 are lower than the average, accounting for $46.67 \%$ of the total, indicating that the transformation efficiency still has a lot of room for improvement. We also use the clustering algorithm based on $K$-means, and its clustering results are shown in Figure 9.

According to the transformation efficiency values and Figure 9, 30 provinces are divided into three categories: good, middle, and poor. The good category includes Beijing, Jiangsu, Guangxi, Hainan, Qinghai, Ningxia, Hebei, Guangdong, Shanxi, Shanghai, Anhui, Chongqing, Tianjin, Jilin, Zhejiang, and Fujian; the middle category includes Henan, Hubei, Shaanxi, Xinjiang, Inner Mongolia,
Shandong, Jiangxi, and Heilongjiang; and the provinces and cities in poor category are Liaoning, Hunan, Sichuan, Guizhou, Yunnan, and Gansu. From the map distribution, the least efficient part of the whole, the third category, is less distributed, and most are the first category. From the east to the west, the overall efficiency of the east is obviously better than that of the west. From the north to the south, the distribution of the third category is mostly concentrated in the west, while the main distribution area of lower efficiency has evolved from the northeast area to the southwest area and some places in the middle area. At the same time, we also notice that the transformation efficiency of Beijing, Tianjin, Jilin, Shanghai, Jiangsu, Guangxi, Qinghai, Ningxia, and other places exceeds the average level and the efficiency values are 1 , indicating that the transformation efficiency of the universities in various provinces and cities can make the input efficiently. For some eastern provinces, the R\&D stage is a barrier to the rapid development of universities and the cultivation of high-quality talents. The number of these provinces and cities accounts for $26.67 \%$ of the country, which shows that there are very few provinces and cities where the transformation efficiency can reach about 1 . In addition, the transformation efficiency of Jiangxi, Inner Mongolia, Sichuan, and other provinces and cities fluctuates near 0.5, and the transformation efficiency of Guizhou, Liaoning, Hunan, Yunnan, and Gansu is lower than 0.5. These figures clearly indicate which provinces and cities need to be improved or maintained. For the provincial and municipal universities in the second category, they should maintain the current advantages of transformation and then take some optimization measures to adjust some deficiencies from the R\&D stage to the transformation stage so as to ensure the sound development of scientific and technological activities in two stages. Meanwhile, the provinces and cities with low transformation efficiency should be encouraged to find their own weaknesses, and they are expected to learn from the provinces and cities with good efficiency, make good use of existing scientific and technological innovation resources, and improve the input- 


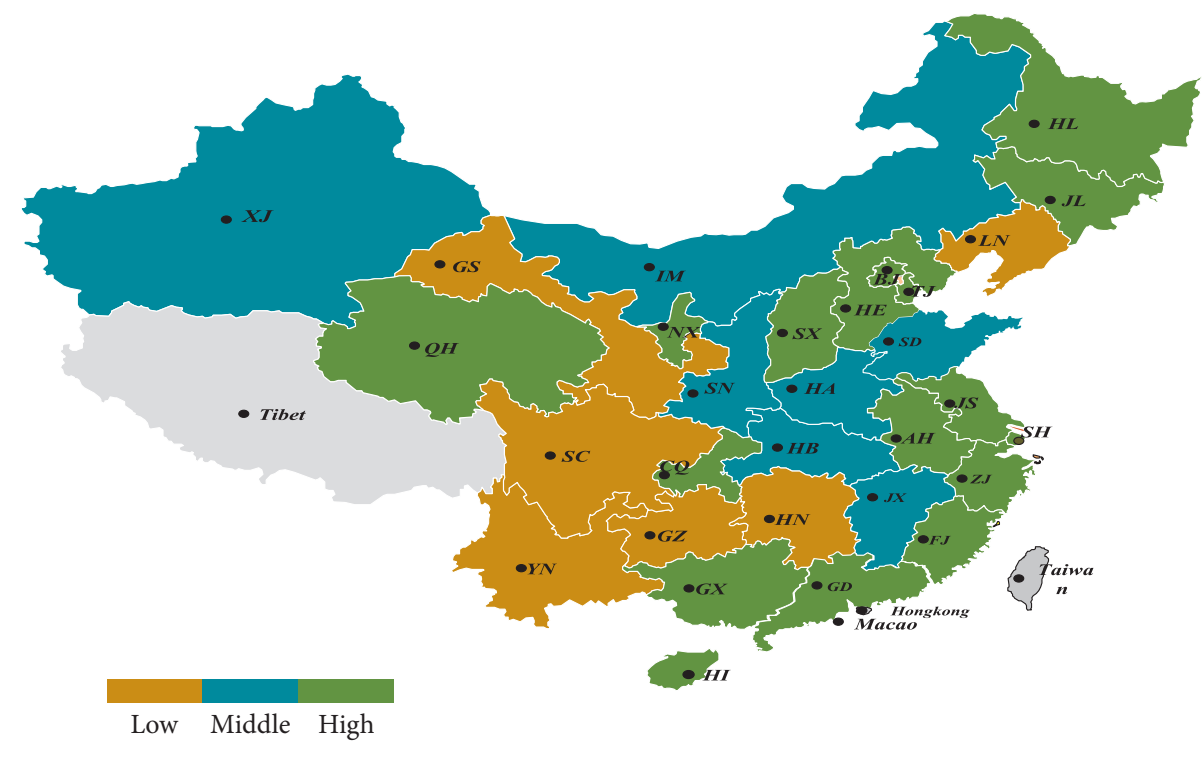

FIGURE 9: Clustering results of transformation efficiency.

output efficiency of $\mathrm{R} \& \mathrm{D}$ funds and personnel so that the achievements of $\mathrm{R} \& \mathrm{D}$ can be transformed into patents, technical secrets, and other intellectual property rights as much as possible, and as a result, these achievements are made to turn into economic benefits, which can serve the society.

(5) The Analysis of the Combination Mode Efficiency. According to the above analysis, it can be concluded that the R\&D efficiency and transformation efficiency jointly affect the comprehensive efficiency. For example, in some provinces, the R\&D efficiency is low, although the efficiency of transformation is high, which ultimately leads to the low comprehensive efficiency. Therefore, it is necessary to further analyze the relationship between $R \& D$ and transformation, and it is important to comprehensively analyze the time and space differences from these two dimensions. By taking the average value of transformation efficiency (0.747) and the average value of R\&D efficiency (0.748) as the vertical and horizontal coordinate dividing lines, respectively, 30 provinces are divided into four types of resource utilization modes including high R\&D-high transformation, low R\&D-high transformation, low R\&D-low transformation, and high R\&D-low transformation, which are shown in Figure 10.

According to Figure 10, four types of resource utilization modes are given as follows:

(1) High R\&D-high transformation type: This type includes 8 provinces and cities: Beijing, Hebei, Jiangsu, Guangdong, Guangxi, Hainan, Qinghai, and Gansu, accounting for $26.67 \%$ of the total. These provinces are mainly from the east and partly from the west. The universities in these areas show a high level at both the R\&D and achievement transformation stages and belong to the mode of efficient and intensive innovation and development. In the following development, such regions should not only maintain their own advantages, but also start from the aspects of process management, simplification of technical links, and so on to make their R\&D and transformation links more concise and efficient. At the same time, they should keep abreast of international development trends and management experience to constantly improve competitiveness. In addition, although Qinghai, Hainan, and other provinces have a relatively high efficiency in the two stages, their R\&D input and output volumes are relatively small and project topics are relatively fixed and single. Therefore, in the future development process, it is important to expand innovation fields appropriately and open up new markets combining with their own conditions.

(2) Low R\&D-high transformation type: This type includes Tianjin, Shanxi, Jilin, Shanghai, Zhejiang, Anhui, Fujian, and Chongqing, accounting for $26.67 \%$ of the total, and they are scattered and mainly come from the east. These provinces have high efficiency at the stage of achievement transformation, but have low efficiency at the R\&D stage of scientific and technological innovation, which restricts the transformation of achievements and the promotion of comprehensive efficiency of universities' scientific and technological activities. Such areas should start from the R\&D stage of scientific and technological innovation and then work out the corresponding steps and processes through the introduction of technology and talent according to their own actual situation. They also need to strengthen the depth and breadth of existing cooperation and pay attention to the introduction of high-tech talents to help their innovative R\&D.

(3) Low R\&D-low transformation type: This type includes 7 provinces and cities: Heilongjiang, Jiangxi, Hunan, Sichuan, Guizhou, Yunnan, and Gansu, 


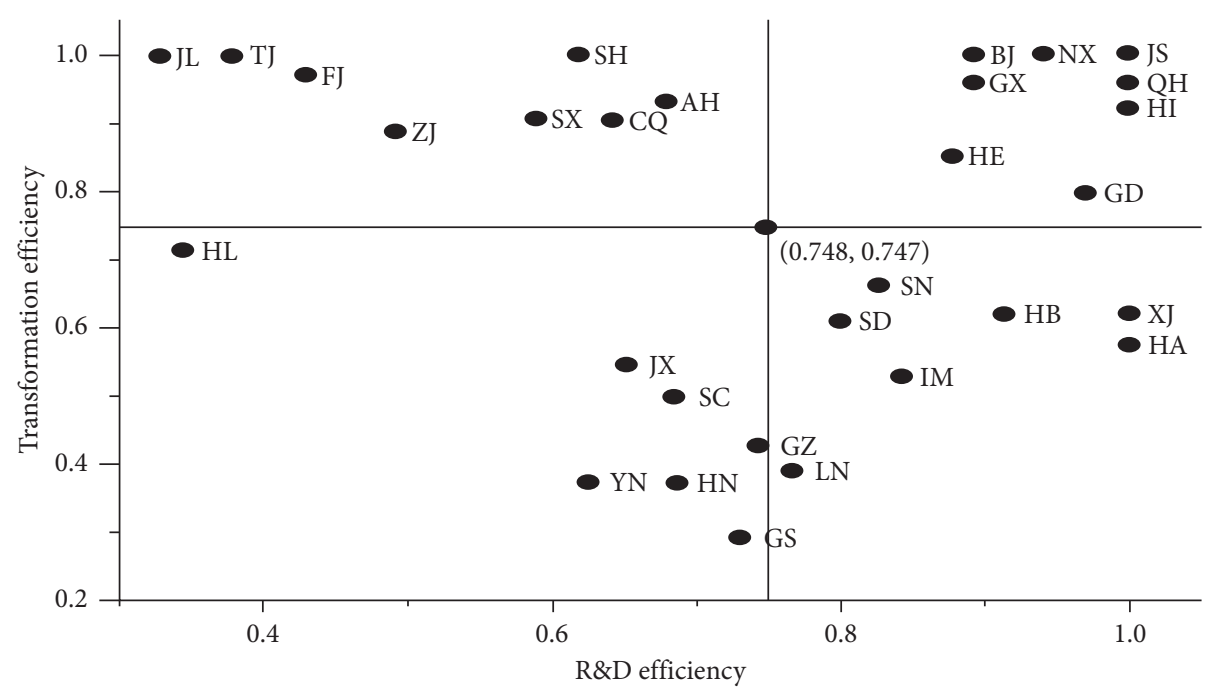

Figure 10: Distribution of provinces under different resource utilization modes.

accounting for $26.67 \%$ of the total, and they are mainly from the west. The efficiency of R\&D and achievement transformation of scientific and technological innovation in these areas are low. They need to make great improvements at both the R\&D and transformation stages and strive to change from double-low type to one high-one low type and then turn into double-high type. If the base of science and technology and economy is better, they can try to transform directly from double-low type to doublehigh type.

(4) High R\&D-low transformation type: This type includes Inner Mongolia, Liaoning, Shandong, Henan, Hubei, Shaanxi, and Xinjiang, accounting for $26.67 \%$, and they are mainly from the middle and the west. These provinces have higher efficiency at the $\mathrm{R} \& \mathrm{D}$ stage but lower efficiency at the stage of achievement transformation. These areas need to start from the transformation of achievements and take advantage of their own positions to strengthen the exchange and cooperation with the provinces and cities in the east. In addition, they should fully understand the needs of the market and combine them with their own situation to work out strategies that are consistent with their own development.

5.3. Identification of Influencing Factors on the Efficiency of Universities' Scientific and Technological Activities. According to the influencing factors on the efficiency of provincial universities' scientific and technological activities and the "Science and Technology Statistical Yearbook of Universities" and "China Education Statistical Yearbook," we select panel data of 30 provincial universities in 7 years from 2010 to 2016 (Tibet, Hong Kong, Macao, and Taiwan are not included in the scope of this study due to lack of data) and normalize them. In this study, we take the efficiency of R\&D and achievement transformation of each provincial university as the explained variables and the influencing factors in the previous model as the explaining variables, and then, we construct a GMM dynamic panel model and perform regression analysis. According to the variable indexes created above, based on the panel data of provincial scientific and technological activity indexes, the regression results of the efficiency of provincial universities' scientific and technological activities are calculated using Stata15.1 programming, which are shown in Table 6.

According to Table 6, the regression model can be obtained as follows:

$$
\begin{aligned}
E_{i t}^{1}= & (-1.903)+0.786 E_{i t-1}^{1}+0.834 \mathrm{HQ}_{i t} \\
& +(-0.0161) \ln \left(\mathrm{COM}_{i t}\right)+0.902 \mathrm{GOV}_{i t}+0.796 \mathrm{ENT}_{i t} \\
& +0.0190 \ln \left(\mathrm{PRO}_{i t}\right)+0.0401 \ln \left(\mathrm{ECO}_{i t}\right), \\
E_{i t}^{2}= & 2.590+0.607 E_{i t-1}^{2}+(-2.375) H Q_{i t} \\
& +0.0332 \ln \left(\mathrm{COM}_{i t}\right)+(-0.849) \mathrm{GOV}_{i t} \\
& +(-0.534) \mathrm{ENT}_{i t}+(-0.0642) \ln \left(\mathrm{PRO}_{i t}\right) \\
& +0.0983 \ln \left(\mathrm{ECO}_{i t}\right) .
\end{aligned}
$$

According to Table 6, the first-order autocorrelation test is less than 0.05, and the second-order and third-order autocorrelation tests are all greater than 0.05 , which means the model has no autocorrelation. The Sargan test is above 0.1 , indicating that the selection of instrumental variables is effective and the model fits well. According to the regression results, it can be found that firstly, for the two stages of universities' scientific and technological activities, the efficiency value of the lag period has a significant positive effect on the current efficiency value. This is due to the nonquantitative factors such as the government's policy system and the influence of endogenous factors (technical service funds, scientific and technological service personnel and institutions) on the efficiency of universities' scientific and technological activities. It shows that the improvement and optimization of the technical level of scientific and technological activities in provincial universities are a gradual 
TABLE 6: Results of influencing factors in two-stage efficiency.

\begin{tabular}{|c|c|c|c|c|c|c|}
\hline \multirow{2}{*}{$\begin{array}{l}\text { Dependent variable } \\
\text { Independent variable }\end{array}$} & \multicolumn{2}{|c|}{ Evrs1 } & \multirow[b]{2}{*}{ Rank } & \multicolumn{3}{|c|}{ Evrs2 } \\
\hline & Coefficient & $Z$ & & Coefficient & Z & Rank \\
\hline L.1evrs & $0.786^{* * *}$ & {$[0.0443]$} & 4 & $0.607^{* * *}$ & {$[0.0320]$} & 1 \\
\hline Government & $0.902^{* * *}$ & {$[0.0857]$} & 1 & $-0.849^{* *}$ & {$[0.2645]$} & 6 \\
\hline Enterprise & $0.796^{* * *}$ & {$[0.1104]$} & 3 & $-0.534^{* *}$ & [0.1983] & 5 \\
\hline Human quality & 0.834 & {$[0.9242]$} & 2 & $-2.375^{* *}$ & {$[0.7369]$} & 7 \\
\hline lncom & -0.0161 & {$[0.0095]$} & 7 & $0.0332^{* *}$ & {$[0.0110]$} & 3 \\
\hline lnpro & $0.0190^{* *}$ & {$[0.0065]$} & 6 & $-0.0642^{* * *}$ & {$[0.0164]$} & 4 \\
\hline Lneco & $0.0401^{* *}$ & {$[0.0129]$} & 5 & $0.0983^{*}$ & {$[0.0451]$} & 2 \\
\hline _cons & $-1.903^{*}$ & {$[0.9037]$} & & $2.590^{* *}$ & {$[0.8753]$} & \\
\hline $\mathrm{AR}(1)$ & \multicolumn{2}{|c|}{0.0129} & & \multicolumn{3}{|c|}{0.0115} \\
\hline AR (2) & \multicolumn{2}{|c|}{0.6728} & & \multicolumn{3}{|c|}{0.7876} \\
\hline AR (3) & \multicolumn{2}{|c|}{0.1429} & & \multicolumn{3}{|c|}{0.9594} \\
\hline Sargan test & \multicolumn{2}{|c|}{0.8805} & & \multicolumn{3}{|c|}{0.4434} \\
\hline
\end{tabular}

Standard errors in brackets. ${ }^{*} p<0.05,{ }^{* *} p<0.01,{ }^{* * *} p<0.001$.

growth process, and the efficiency value of the lag period in the transformation stage of the results has a greater impact on the current efficiency value. Secondly, in the R\&D stage, the government support, the quality of R\&D personnel, the connection between universities and enterprises, the number of R\&D topics, and the regional economic development have positive effects on the efficiency of scientific and technological activities. The scientific and technological exchange activities of universities have a negative correlation with the R\&D of universities, and their influence on the efficiency of scientific and technological activities in universities is decreasing. It shows that the government support, the quality of R\&D personnel, and the connection between universities and enterprises are important factors influencing the R\&D efficiency of universities' scientific and technological activities, and $\mathrm{R} \& \mathrm{D}$ topics and regional economic development are secondary influencing factors. Thirdly, in the stage of achievement transformation, the transformation of scientific and technological achievements, the number of projects, and regional economic development are important factors in the transformation efficiency of scientific and technological achievements in universities, while the R\&D personnel, government, and enterprise support funds have not improved the efficiency of scientific and technological achievements. It is true that more scientific and technological exchanges and project cooperation have promoted the scientific and technological achievements, and it is true that the regions with better regional economic development have the ability to implement the transformation of results.

\section{Conclusions}

Based on the perspective of the innovation value chain, we exploit the DEA model with shared input to measure the efficiency of universities' scientific and technological activities, and we explore the provincial universities' efficiency differences and analyze the influencing factors. According to the empirical analysis, there exist the following results. The results show that there are serious problems in knowledge output and results transformation in the universities' scientific and technological activities. The scientific and technological activities of regional universities in China are not balanced. For provincial universities' efficiency of scientific and technological activities, there exist great differences among different time and space, stages, and resource utilization modes. The endogenous factors such as policy system and technology service are much more important factors.

(1) There are serious problems in the transformation of knowledge output, and it results in the universities' scientific and technological activities, and it is more serious that production and research went off the rails.

(2) The scientific and technological activities of regional universities in China are not balanced. From the perspective of comprehensive efficiency, the overall efficiency of the eastern region and the western region is similar, which is higher than the national average comprehensive efficiency, and the comprehensive R\&D efficiency of the central region and the northeast region is relatively low. From the perspective of $\mathrm{R} \& \mathrm{D}$ efficiency, the western region has a large advantage, and the northeast region has a large gap with the eastern and central regions. From the perspective of transformation efficiency, the values of the transformation efficiency in the eastern region are generally high, and the transformation ability in the western region is very strong.

(3) For provincial universities' efficiency of scientific and technological activities, there exists a great difference among different time and space, stages, and resource utilization modes.

(4) The endogenous factors such as policy system and technology service are much more important factors. Meanwhile, the influencing factors at different stages are different. For example, government support, quality of R\&D personnel, and the connection between universities and enterprises are the key factors affecting the R\&D efficiency of universities' scientific and technological activities; scientific and technological exchanges, number of projects, and regional 
economic development are important factors in the efficiency of university scientific and technological achievements.

However, this article also has certain limitations. Due to the limitation of data acquisition, the evaluation indicator system for universities' scientific and technological activity efficiency constructed in this study is not comprehensive and detailed enough. Some relevant important universities' scientific and technological activity indicators were not included. From a realistic perspective, the lag period for different universities' scientific and technological activity efficiency evaluation indicators is generally different. Therefore, how to construct a two-stage network DEA model with different lag periods and shared input to measure the efficiency of universities' scientific and technological activities is our future research direction.

\section{Data Availability}

The data used to support the findings of this study are available from the corresponding author upon request (huan983405544@163.com).

\section{Conflicts of Interest}

The authors declare that they have no conflicts of interest.

\section{Acknowledgments}

This work was partially funded by the National Social Science Foundation of China (19FGLB031); National Vocational College Teachers' Teaching Innovation Team Construction Systematic Research Project (TX20200801); Outstanding Youth in Social Sciences of Jiangsu Province; Qinglan Project of Jiangsu Province, Fundamental Research Funds for the Central Universities (JUSRP321016), and Major Project of Philosophy and Social Science Research in Jiangsu Universities (2019SJZDA046); Philosophy and Social Science Research Project of Jiangsu Province University; Research Achievement of Jiangsu Province Social Science Foundation Project (19TQD006); Research Project of Philosophy and Social Sciences in Colleges and Universities of Jiangsu Province (Special Project of Ideological and Political Work) (2020SJB0361); and Wuxi Association for Science and Technology Soft Science (KX21-C-45).

\section{References}

[1] C. Grimpe and K. Hassinger, "Formal and informal knowledge and technology transfer from academia to industry: complementarity effects and innovation efficiency," Industry and Innovation, vol. 20, no. 8, pp. 683-700, 2013.

[2] T. Serdal and G. Brian, "Examining university-industry collaboration as a source of innovation in the emerging economy of Turkey," International Journal of Innovation Science, vol. 5, no. 1, pp. 81-88, 2013.

[3] F. Liu, W. Zhu, Y. Chen, and D.-1. Xu, "Evaluation, ranking and selection of R\&D projects by multiple experts: an evidential reasoning rule-based approach," Scientometrics, vol. 111, no. 3, pp. 1501-1519, 2017.
[4] Y. T. Lei, M. J. Yu, and Z. Q. Liang, "Analysis of the problems faced by the industrialization of scientific and technological achievements in Universities," R\&D Management, vol. 19, no. 1, pp. 133-135, 2007.

[5] C. H. Jiao and Y. F. Chen, "R\&D resource allocation, spatial correlation and regional total factor productivity improvement," Studies in Science of Science, no. 1, pp. 81-92, 2018.

[6] W. Zhang and X. L. Yang, "Research on the role and orientation of universities and $\mathrm{R} \& \mathrm{D}$ institutions in national innovation system," R\&D Management, vol. 18, no. 4, pp. 97-103, 2006.

[7] K. Gupta, R. Banerjee, and I. Onur, "The effects of R\&D and competition on firm value: international evidence," International Review of Economics \& Finance, vol. 51, pp. 391-404, 2017.

[8] Y. J. Feng, H. Lu, and K. Bi, "An AHP/DEA method for measurement of the efficiency of R\&D management activities in universities," International Transactions in Operational Research, vol. 11, no. 2, pp. 181-191, 2004.

[9] R. Bronzini and P. Piselli, "The impact of R\&D subsidies on firm innovation," Research Policy, vol. 45, no. 2, pp. 442-457, 2016.

[10] O. W. Maietta, "Determinants of university-firm R\&D collaboration and its impact on innovation: a perspective from a low-tech industry," Research Policy, vol. 44, no. 7, pp. 1341-1359, 2015.

[11] J. Baumann and A. S. Kritikos, "The link between R\&D, innovation and productivity: are micro firms different?" Research Policy, vol. 45, no. 6, pp. 1263-1274, 2016.

[12] W. Chapple, A. Lockett, D. S. Siegel, and M. Wright, "Assessing the relative efficiency of U.K. university technology transfer offices: parametric and non-parametric evidence," Research Policy, vol. 34, no. 3, pp. 369-384, 2005.

[13] D. C. Fan and S. N. Li, "Research on technology innovation efficiency of High-tech industry considering space effect," Studies in Science of Science, vol. 36, no. 5, pp. 901-912, 2018.

[14] D. S. Siegel, D. Waldman, and A. Link, "Assessing the impact of organizational practices on the relative productivity of university technology transfer offices: an exploratory study," Research Policy, vol. 32, no. 1, pp. 27-48, 2003.

[15] T. Agasisti, E. Shibanova, D. Platonova, and M. Lisyutkin, "The Russian excellence Initiative for higher education: a nonparametric evaluation of short-term results," International Transactions in Operational Research, vol. 27, no. 4, pp. 1911-1929, 2020.

[16] W. Chen, X. X. Li, and G. L. Yang, "A comparative study of technology transfer efficiency between Chinese and foreign Universities: based on DEA-Malmquist method," Science of Science and Technology Management, vol. 7, pp. 98-106, 2014.

[17] B. He and S. Fan, "Evolution and influencing factors of transformation efficiency of science and technology achievements in Chinese universities: analysis based on bootstrap-DEA method and panel tobit model," Science of Science and Management of S. \& Technology, vol. 34, no. 10, pp. 85-94, 2013.

[18] X. Xi, G. L. Yang, and Z. C. Guan, “Assessing R\&D efficiency using a two-stage dynamic DEA model: a case study of research institutes in the Chinese Academy of Sciences," Journal of Informetrics, vol. 12, no. 3, pp. 784-805, 2018.

[19] D. Q. Zhang, R. D. Banker, X. X. Li, and W. Liu, "Efficiency impact of research policy at the Chinese Academy of Sciences," Research Policy, vol. 40, no. 6, pp. 875-885, 2011.

[20] Y. Liu, X. Y. Xiong, and B. T. Quan, "Bilateral fair matching decision model based on grey relational analysis and its 
application," Chinese Journal of Management, vol. 14, no. 1, pp. 86-92, 2017.

[21] S. Immwen and L. L. Cooksy, "Using efficiency measurement to assess research: lessons learned from the international agricultural research centers," Evaluation, vol. 20, no. 1, pp. 96-114, 2014.

[22] Y. B. Lei, H. Li, and G. L. Ou, "Efficiency evaluation and research of Chinese research institutes based on government science and technology investment," Science of Science and Management of S\& T, vol. 22, no. 7, pp. 34-33, 2010.

[23] N. Salimi and J. Rezaei, "Evaluating firms' R\&D efficiency using best-worst method," Evaluation and Program Planning, vol. 66, p. 147, 2018.

[24] Y. Liu, B. T. Quan, and H. Li, "A delay grey incidence analysis framework for assessing drivers and obstacles of R\&D efficiency at Chinese universities," Grey Systems: Theory and Application, vol. 8, no. 1, pp. 2-13, 2018.

[25] J. X. Hou and L. Y. Hou, "Evaluation factors and ranking of scientific and technological achievements in local universities," Research Management, vol. 37, pp. 476-481, 2016.

[26] C. Kao and H. T. Hung, "Efficiency analysis of university departments: an empirical study," Omega, vol. 36, no. 4, pp. 653-664, 2008.

[27] J. Lane and S. Bertuzzi, "Measuring the results of science investments," Science, vol. 331, no. 6018, pp. 678-680, 2011.

[28] X. B. Li and F. Xie, "An empirical study on the influencing factors of knowledge production and innovation activities in Chinese universities," Quantitative Economics of Economics and Technology, no. 1, pp. 39-53, 2013.

[29] S. C. Ray, "Resource-use efficiency in public schools: a study of Connecticut data," Management Science, vol. 37, no. 12, pp. 1620-1628, 1991.

[30] D. S. Siegel and P. D. Phan, Analyzing the Effectiveness of University Technology Transfer: Implications for Entrepreneurship Education, Rensselaer Polytechnic Institute, Troy, NY, USA, 2005.

[31] C. D. T. T. Tran and R. A. Villano, "Measuring efficiency of Vietnamese public colleges: an application of the DEA-based dynamic network approach," International Transactions in Operational Research, vol. 25, no. 2, pp. 683-703, 2018.

[32] H. F. Song, B. Wu, and L. Lv, "Research on promoting the transformation of science and technology achievements into intellectual property rights implementation system," Scientia Research, vol. 9, pp. 1319-1325, 2016.

[33] J. Zhang, C. Huang, X. Ye, K. Shi, and W. Su, "A quantitative research on the spread of China's public policy_taking the transformation policy of scientific and technological achievements as an example," China Soft Science, vol. 2, pp. 145-155, 2016.

[34] C. Claudia, D. Cinzia, and L. Patrick, "University technology transfer: how (in) efficient are French universities," Cambridge Journal of Economics, vol. 36, no. 3, pp. 629-654, 2012.

[35] M. T. Hansen and J. Birkinshaw, "The innovation value chain," Harvard Business Review, vol. 85, no. 6, pp. 121-130, 2007.

[36] B. N. Fan and W. Yu, "Research on regional differences and influential factors of technology transfer efficiency in universities," Studies in Science of Science, vol. 33, no. 12, pp. 1805-1812, 2015.

[37] G. Huang, W. P. Xu, and Y. Li, "Technology value chain and link model of innovation subjects," China Soft Science, vol. 6, pp. 67-75, 2006.

[38] P. Rothwell, "Successful industrial innovation: critical factors for the 1990s," R\&D Management, vol. 22, no. 3, pp. 221-239, 1992.
[39] Y. Liu, H. B. Ying, and F. J. Jiang, "Comparison of science and technology innovation capabilities of Chinese universities: an empirical study based on universities in east China," R\&D Management, vol. 5, pp. 113-119, 2014.

[40] K. Rao, X. F. Meng, L. Xu, and P. Andrea, "The impact of R\& $\mathrm{D}$ investment on technology transfer contracts in Chinese universities," Management Science, vol. 25, no. 5, pp. 76-84, 2012.

[41] Z. J. Yu, C. H. Yang, Y. Bai, and Z. L. Peng, "Research on the innovation efficiency and influencing factors of universities from the perspective of achievement type," Scientific Research Management, vol. 38, no. 5, pp. 141-149, 2017.

[42] S. Doh and B. Kim, "Government support for SME innovation in the regional industries: the case of government financial support program in South Korea," Research Policy, vol. 43, no. 9, pp. 1557-1569, 2014.

[43] D. Y. Yu and X. R. Jin, "Innovation efficiency evaluation of the innovation subjects and their regional difference," Science Research Management, vol. 35, no. 3, pp. 51-57, 2014.

[44] K. H. Chen and J. C. Guan, "Network DEA based efficiency measurement and decomposition for a relational two-stage production system with shared input," Systems engineering theory and practice, vol. 31, no. 7, pp. 1211-1221, 2011.

[45] L. Liang, F. Yang, W. D. Cook, and J. Zhu, "DEA models for supply chain efficiency evaluation," Annals of Operations Research, vol. 145, no. 1, pp. 35-49, 2006.

[46] J. Ma, L. Qi, and L. Deng, "Additive centralized and Stackelberg DEA models for two-stage system with shared resources," International Transactions in Operational Research, vol. 27, no. 4, pp. 2211-2229, 2020. 